\title{
Anti-immigrant prejudice: understanding the roles of (perceived) values and value dissimilarity
}

Article

Accepted Version

Wolf, L. J., Weinstein, N. ORCID: https://orcid.org/0000-0003-

2200-6617 and Maio, G. R. (2019) Anti-immigrant prejudice:

understanding the roles of (perceived) values and value dissimilarity. Journal of Personality and Social Psychology, 117 (5). pp. 925-953. ISSN 1939-1315 doi:

https://doi.org/10.1037/pspi0000177 Available at https://centaur.reading.ac.uk/93582/

It is advisable to refer to the publisher's version if you intend to cite from the work. See Guidance on citing.

To link to this article DOI: http://dx.doi.org/10.1037/pspi0000177

Publisher: American Psychological Association

All outputs in CentAUR are protected by Intellectual Property Rights law, including copyright law. Copyright and IPR is retained by the creators or other copyright holders. Terms and conditions for use of this material are defined in the End User Agreement. 


\section{CentAUR}

Central Archive at the University of Reading

Reading's research outputs online 
CAmerican Psychological Association, [2018]. This paper is not the copy of record and may not exactly replicate the authoritative document published in the APA journal.

Anti-Immigrant Prejudice: Understanding the Roles of (Perceived) Values and Value Dissimilarity

$$
\begin{aligned}
& \text { Lukas J. Wolf }{ }^{1,2} \\
& \text { Netta Weinstein }{ }^{1} \\
& \text { Gregory R. Maio }{ }^{2}
\end{aligned}
$$

${ }^{1}$ School of Psychology, 70 Park Place, Cardiff University, Cardiff, CF10 3AT, UK

${ }^{2}$ Department of Psychology, Claverton Down, University of Bath, Bath, BA2 7AY, UK L.Wolf@bath.ac.uk

WeinsteinN@cardiff.ac.uk

G.R.Maio@bath.ac.uk

Corresponding author: Lukas J. Wolf, email: L.Wolf@bath.ac.uk 


\begin{abstract}
Although human values and value dissimilarity play pivotal roles in the prejudice literature, there remain important gaps in our understanding. To address these gaps, we recruited three British samples $(N=350)$ and presented Muslim immigrants, refugees, and economic migrants as target groups. Using polynomial regression analyses, we simultaneously tested effects of individuals' own values, their perceptions of immigrant values, and self-immigrant value dissimilarities on prejudice. Results indicated that favorability toward immigrants is higher when individuals hold higher self-transcendence values (e.g., equality) and lower selfenhancement values (e.g., power), and when they perceive immigrants to hold higher selftranscendence values and lower self-enhancement values. In addition, prejudice toward immigrants is higher when individuals who hold higher conservation values (e.g., security) perceive immigrants to value openness (e.g., freedom) more, suggesting a value dissimilarity effect. No value dissimilarity effects emerged when immigrants were perceived to be higher in conservation, self-transcendence, or self-enhancement values. Overall, these results showed that effects of values and value dissimilarity differ depending on which value dimension is considered. Additionally, the results revealed support for a novel mechanism with the motivation to be non-prejudiced underpinning the links between individuals' values and prejudice. Our discussion highlights the multifaceted manner in which values are linked to prejudice.
\end{abstract}

Keywords: Human values, Prejudice, Dissimilarity, Immigrants 


\section{Anti-Immigrant Prejudice:}

\section{Understanding the Roles of (Perceived) Values and Value Dissimilarity}

Exacerbated by the civil war in Syria and political unrest in the Middle East, 2015 has seen more than 244 million international migrants and 65 million refugees - the highest numbers on record (UNHCR, 2016). Among EU countries, the UK was the second largest receiver of immigrants, with an estimated 631,500 people entering the UK in 2015 (eurostat, 2017; Office for National Statistics, 2017). Given these figures, the UK provides an important opportunity for examining the public reaction to the immigration crisis. According to a YouGov poll in November 2015 (YouGov, 2015; see also BBC, 2016), 49\% of British respondents wanted to see a reduction in the admission of Syrian refugees, and $74 \%$ wanted to see a reduction in the admission of economic migrants. Evidently, the influx of immigrants (and the prospect thereof) has evoked a predominantly negative response among the British public.

In line with these findings within the UK, research in recent decades has generally revealed evidence of prejudice and discrimination against immigrants (e.g., Akrami, Ekehammar, \& Araya, 2000; Pettigrew \& Meertens, 1995). This research has also identified a range of predictors of prejudice, including personality traits, conflict over economic resources, and, importantly for this work, human values (e.g., Bernard, Maio, \& Olson, 2003; Dunwoody \& McFarland, 2017; Esses, Dovidio, Jackson, \& Armstrong, 2001; Heaven, Organ, Supavadeeprasit, \& Leeson, 2006; Rohan, 2000). Values can be defined as abstract ideals (e.g., equality, freedom, success) that provide important guiding principles in people's lives (Rokeach, 1968; Schwartz, 1992). While there has been a substantial body of work on how values relate to prejudice (e.g., Rokeach, 1973; Vecchione, Caprara, Schoen, Castro, \& Schwartz, 2012), there remain significant gaps in our understanding.

First, although considerable research attention has been devoted to examining prejudice as a function of value dissimilarities between the self or the ingroup and the 
outgroup (e.g., Haddock, Zanna, \& Esses, 1993; Struch \& Schwartz), this research has employed analytical methods that are likely to have overstated or misrepresented the role of value dissimilarity in prejudice (Edwards, 1993, 1994, 2002; Griffin, Murray, \& Gonzalez, 1999). Second, this line of research has ignored the possibility that value dissimilarity effects may differ depending on which types of values are considered (Abbott, White, \& Charles, 2005; Finegan, 2000). Third, while values have been conceptualized as having a motivational basis, research has not yet considered whether the link between abstract values and prejudice toward outgroups can be explained by more specific motivations to regulate one's level of prejudice. And finally, to the best of our knowledge, only one project has examined links between prejudice and people's personal perceptions of other cultural groups' values (Schwartz, Struch, \& Bilsky, 1990), and this work has not tested a role for perceived values that is independent of individuals' own values.

An immigration context provides an important setting for testing value dissimilarity effects, because relations among immigrants and home country nationals may involve fundamental differences in language and cultural values (Dovidio \& Esses, 2001), fueling beliefs about threats to personal values and prejudice (Hitlan, Carrillo, Zárate, \& Aikman, 2007). The present three studies aimed to address gaps in understanding the role of values in prejudice toward immigrant groups using an improved analytical method, polynomial regression analyses, which simultaneously examines effects of individuals' own values, their beliefs about immigrants' values, and value dissimilarities. This novel method allowed us to comprehensively test these effects independently of each other on prejudice in a current immigration context, and it allowed us to tease apart effects of different types of values. In addition, we sought to advance the theoretical understanding of how abstract values relate to prejudice by testing whether the motivation to be non-prejudiced (Legault, Green-Demers, Grant, \& Chung, 2007) can account for the link between values and prejudice in mediation analyses. Before establishing the theoretical background on how values relate to prejudice, 
we first describe the current analytical approach and how it goes beyond previously used methods.

\section{Current Analytical Approach}

The present research used polynomial regression analyses along with response surface analyses plots to examine how values and value dissimilarity relate to prejudice toward immigrants. This analytical approach, specifically designed to answer questions about dissimilarity effects, redresses shortcomings of previous methods that operationalized value dissimilarity either as (absolute) difference scores (e.g., Dunbar, Saiz, Stela, \& Saez, 2000; Haddock et al., 1993) or as correlations between individuals' own or their ingroup values and their perceived values of the outgroup (Schwartz et al., 1990; Struch \& Schwartz, 1989). Despite their intuitive appeal, both of these analytical methods have important limitations (Edwards, 1993, 2002; Griffin et al., 1999).

First, (absolute) difference scores reduce an inherently three-dimensional relationship between the component measures (here: own and perceived values) and the outcome (here: prejudice) to an ambiguous two-dimensional one. As a result of this reduction, important information is discarded, such as an individual's standing on the component measures. This neglect makes it impossible to examine more closely where dissimilarity effects occur along the levels of the component measures. Second, difference or absolute difference scores confound a dissimilarity effect with the contributions of their component measures. That is, the finding that a higher (absolute) difference between own and perceived values relates to higher prejudice does not necessarily reflect a dissimilarity effect. Instead, such a difference may simply reflect, for example, that own values predict prejudice strongly whereas perceived values are unrelated to prejudice. Third, the relative contributions of the component measures are especially problematic when the measures have unequal variances. This is because (absolute) difference scores give greater weight to measures with larger variance, thereby further complicating interpretations of the effects. Fourth, (absolute) difference scores are 
often less reliable than their component measures. For instance, Edwards (2002) stated that when the component measures are positively correlated at .40, have unit variances, and show reliabilities of .75 , the reliability of the resulting difference score drops to .58 . This is particularly an issue in the present research, because own and perceived values can be expected to correlate substantially. And finally, difference scores and absolute difference scores impose several constraints on the relationships between the component measures and the outcome, and these constraints are rarely tested (for a detailed discussion of these constraints, see Edwards, 2002).

A second analytical approach, profile correlations, reveals similar issues as (absolute) difference scores (Edwards, 1993, 1994, 2002). First, they also reduce a three-dimensional relationship to an ambiguous two-dimensional one and thereby discard information essential to testing dissimilarity effects, including an individual's standing on the component measures and the magnitude of differences between the component measures. Accordingly, profile correlations may indicate a similarity effect despite large discrepancies (but similar shapes) between scores on the component measures. Second, profile correlations similarly confound a dissimilarity effect with the contributions of their component measures and hence introduce conceptual ambiguities in interpreting the results. Third, they typically provide a reliable estimate only when they are based on at least 250 items per component measure (Schönbrodt \& Perugini, 2013). And finally, profile correlations as a measure of dissimilarity may be particularly problematic in the present research where individuals provided scores for both component measures. This is because in this case the resulting dissimilarity index may be strongly confounded by response biases. Hence, overall, operationalizing value dissimilarities as (absolute) difference scores or as profile correlations poses serious issues for the interpretability of the results and often does not provide an index of actual value dissimilarity.

To address these limitations, Edwards (2002) proposed polynomial regression analyses, which regress an outcome variable (i.e., prejudice) onto the linear terms of two 
predictors (i.e., own values and perceived values), their quadratic terms, and their interaction term (for excellent overviews of this analytical approach, see Barranti, Carlson, \& Côté, 2017; Humberg Nestler, \& Back, 2018). This analytical approach (1) does not conceal or distort information about a dissimilarity effect, (2) allows for inspection of the contributions of the component measures, (3) examines a dissimilarity effect separately from the contributions of the component measures, (4) gives an indication of the strength of this effect, (5) does not suffer from reduced reliabilities, (6) deals with unequal variances of the component measures by standardizing them, and, more generally, (7) examines the relationship between component measures and outcomes in a three-dimensional space instead of simplifying it (Edwards, 2002; Barranti et al., 2017).

Another advantage of this analytic approach is that the complex interplay between linear, quadratic, and interactive effects can be plotted in three-dimensional space using response surface analyses (RSA), allowing for visual inspection of the effects. Figure 1 shows four example RSA plots illustrating each of these effects. The component measures, own values and perceived values, are represented on the $\mathrm{X}$ and $\mathrm{Y}$ axes, ranging from -2 to +2 around the scales' midpoints. The outcome, here evaluation of the outgroup, is represented on the vertical $\mathrm{Z}$ axis. Colors tending toward green (light gray) indicate more favorability and colors tending toward red (dark gray) indicate less favorability. The RSA plot displays a surface of the expected values of outgroup evaluation at all possible combinations of own values and perceived values, given the effects obtained from the polynomial regression analysis. For example, the interaction effect in Figure 1d shows that the expected values of outgroup evaluations are more favorable at high levels of both own and perceived values (top back corner) and at low levels of both predictors (top front corner). In contrast, evaluations are less favorable at high levels of own values and low levels of perceived values (bottom right corner). 
a

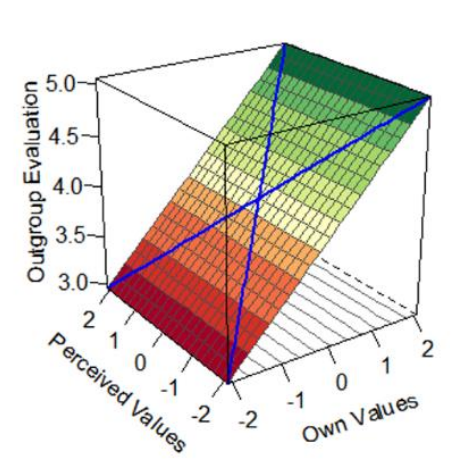

C

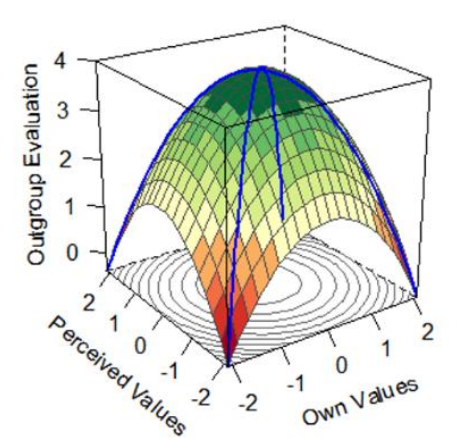

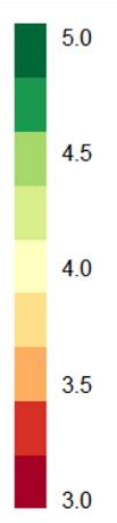

b

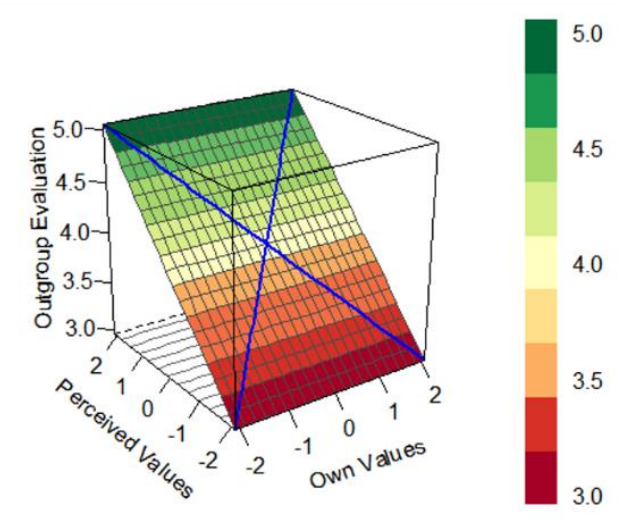

d

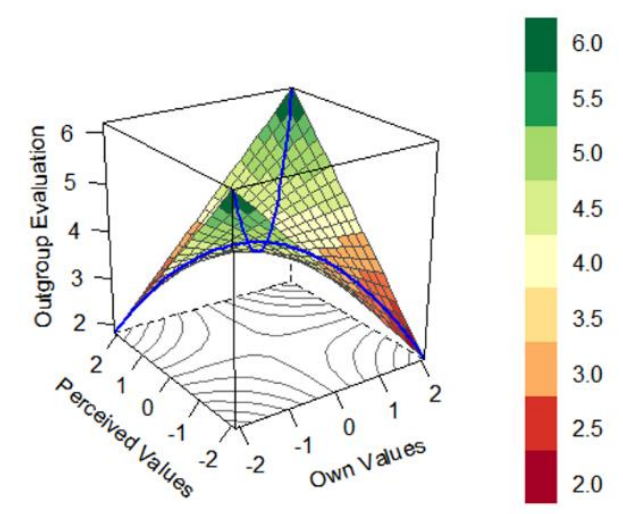

Figure 1. Examples of response surface analyses plots to illustrate linear effects of own values on the $\mathrm{X}$ axis (section a) of perceived values on the $\mathrm{Y}$ axis (section $\mathrm{b}$ ), negative quadratic effects of both own and perceived values (section c), and an interactive effect between own and perceived values (section d). Colors tending toward green (light gray) indicate more positive outgroup evaluations and colors tending toward red (dark gray) indicate more negative outgroup evaluations.

Importantly, as can be seen in the hypothetical example in Figure 2a, a dissimilarity effect between participants' own and perceived values is a function of a strong interactive effect (i.e., $\beta=.50$ ) and moderate negative quadratic effects (i.e., $\beta=-.25$ ). Here, evaluations are most favorable when they are closer to the line of similarity, running from scores of $-2 /-2$ to $+2 /+2$ on the two predictors respectively, and most unfavorable when they are closer to the points of dissimilarity at $-2 /+2$ and $+2 /-2$. In the event that dissimilarity effects emerge in the presence of positive linear effects of own and perceived values, the surface may be somewhat inclined as shown in the hypothetical example depicted in Figure 2b. Generally, 
we focused on the interaction term as an indicator of a possible dissimilarity effect and evaluated it in the light of the other effects.

a

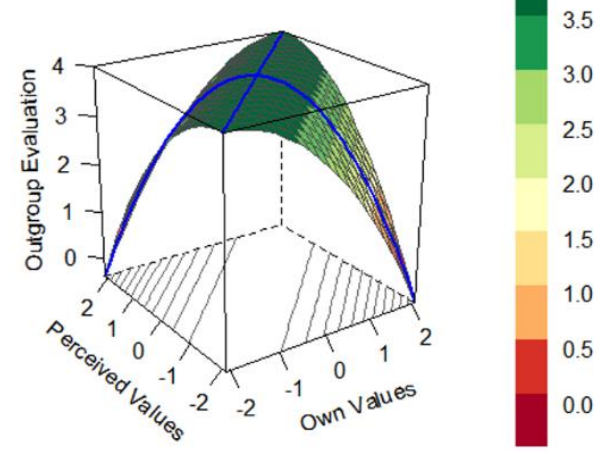

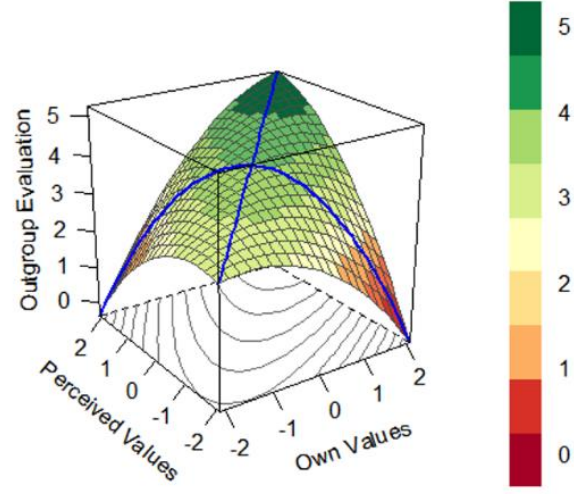

Figure 2. Examples of response surface analyses plots to illustrate a perfect dissimilarity effect between own values and perceived values (section a): outgroup evaluations are highest (i.e., tending more toward green/light gray) when own values and perceived values are closer to the line of similarity, running from scores of $-2 /-2$ to $+2 /+2$ for the two predictors respectively. A perfect dissimilarity effect is a function of a strong interactive effect and moderate negative quadratic effects of each variable. Section b shows a dissimilarity effect under the influence of two moderate linear effects.

Hence, the present research applied polynomial regression analyses and response surface analyses plots to examine the effects of own values, perceived values, and value dissimilarity on prejudice toward immigrants. In addition, as we will see below, these analyses were complemented with mediation analyses to examine whether more specific motivations can explain the link between individuals' abstract values and prejudice toward immigrants. This comprehensive approach provides a tool that is well-suited to representing the multi-faceted way in which values may relate to prejudice.

\section{Individuals' Own Values}

We draw on the comprehensive and well-established circumplex model of values (Schwartz, 1992; Figure 3), because one major aim of the present research was to examine 
effects of different types of values for the first time. According to this model, values are lifeguiding principles whose importance stems from their power to transcend specific situations and objects (Maio, 2016; Rokeach, 1973; Schwartz, 1992). The model proposes that values can be organized along two orthogonal dimensions: self-transcendence versus selfenhancement values and openness versus conservation values. The former dimension contrasts the value types benevolence and universalism, which transcend personal interests to consider the welfare of others (i.e., self-transcendence values), with the value types power and achievement, which promote the self (i.e., self-enhancement values). The latter dimension contrasts the value types conformity, security, and tradition, which promote the status quo (i.e., conservation values) with the value types self-direction and stimulation, which promote intellectual and emotional interests in uncertain directions (i.e., openness values). 


\section{Self-Transcendence}

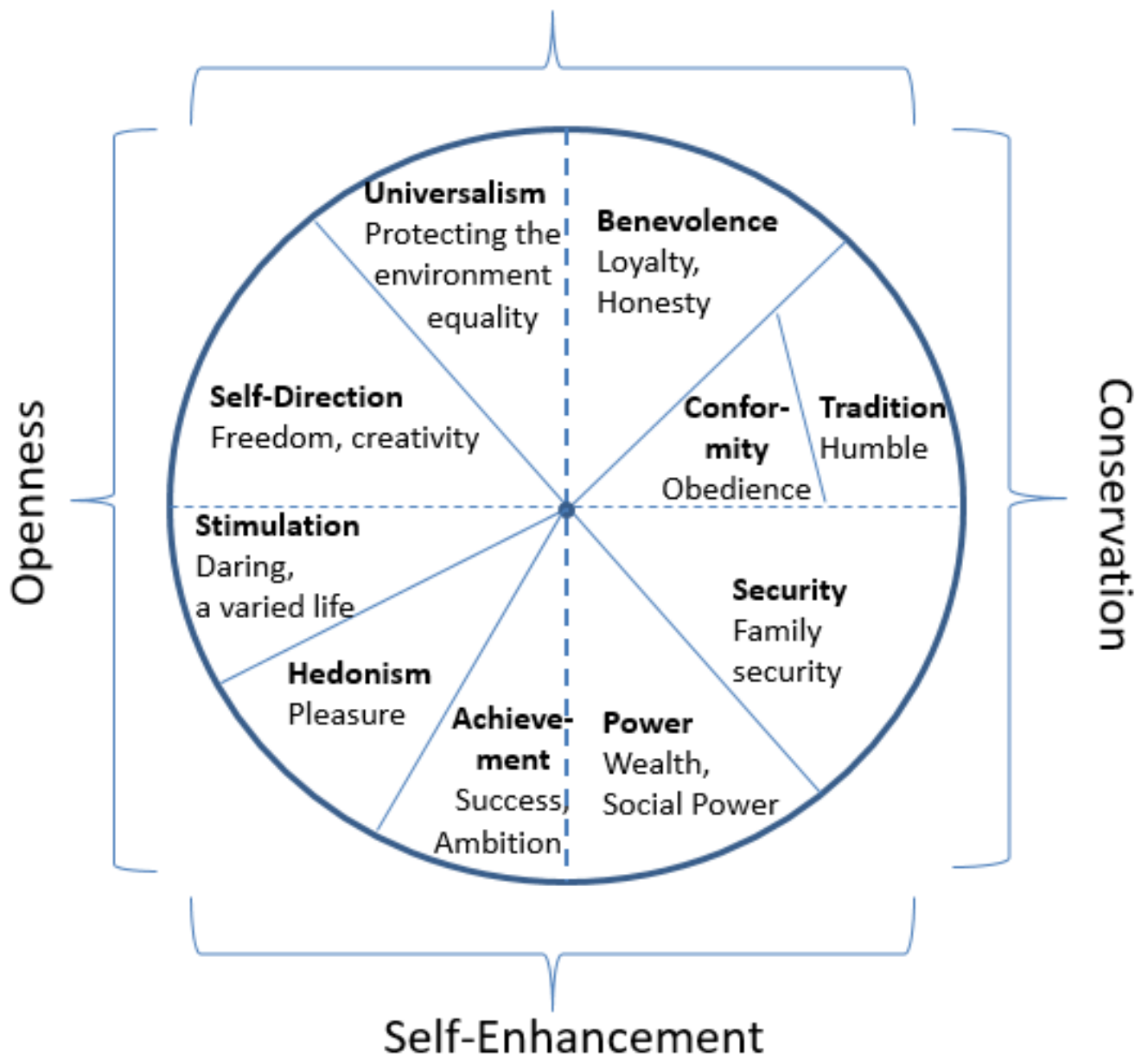

Figure 3. Schwartz's (1992) circumplex model depicting two orthogonal dimensions.

These values predispose people to express more positive or more negative attitudes and behaviors toward outgroups, and immigrants in particular. For instance, people who attach more importance to equality or other self-transcendence values have been found to be less prejudiced toward outgroups (Rokeach, 1973; Sagiv \& Schwartz, 1995), and more favorable and accepting of immigrants and immigration (Bernard et al., 2003; Davidov, Meuleman, Billiet, \& Schmidt, 2008; Schwartz, 2007; Schwartz, Caprara, \& Vecchione, 2010; Vecchione et al., 2012). In contrast, there is some evidence that self-enhancement values are linked with more prejudice toward immigrants (Leong \& Ward, 2006; Saroglou, Lamkaddem, Van Pachterbeke, \& Buxant, 2009). Further, individuals who attach more importance to security or other conservation values are less favorable toward immigrants and 
immigration (Davidov et al., 2008; Schwartz, 2007; Schwartz et al., 2010; Vecchione et al., 2012), and less willing to engage in closer contact with the outgroup (Sagiv \& Schwartz, 1995). In contrast, people who attach more importance to openness values are more favorable toward immigrants (Schwartz et al., 2010) and are more willing to engage in closer contact with minority groups (Roccas \& Amit, 2011; Sagiv \& Schwartz, 1995). These patterns show opposing effects of the values at opposite ends of each value dimension (i.e., selftranscendence vs. self-enhancement, conservation vs. openness), as predicted by Schwartz's (1992) model.

While these explanations are congruent with the definitions of values in Schwartz's model (Sagiv \& Schwartz, 1995), the theorized motivating nature of values may suggest a different indirect mechanism which has not yet been explored. That is, values, which are relatively abstract, may be linked to prejudice through a motivation to be non-prejudiced, a construct which is concrete and specific to the context (Legault et al., 2007). Individual differences in this construct range from an internalized or self-regulated motivation to be nonprejudiced to an externally regulated motivation. There is initial evidence for this mechanism in past research showing that individuals with a more internalized motivation exhibit lower bias than individuals with a more external motivation (Legault et al., 2007; Legault, Gutsell, \& Inzlicht, 2011). Moreover, this research showed that providing reasons for non-prejudice such as equality, social justice, and peace (relating to self-transcendence values) promotes a more internalized motivation for non-prejudice toward Black people than providing reasons such as wanting to be liked and avoiding conflict (relating to self-enhancement and conservation values; Legault et al., 2011). Hence, although this past research targeted more or less internalized reasons for non-prejudice, it also provides indirect support for the notion that values may play a role in shaping the motivation to be non-prejudiced.

To the best of our knowledge, past research has not yet considered the role of specific motivations in linking values and prejudice. By complementing the polynomial regression 
approach with mediation analyses, the present work examined the extent that motivation to be non-prejudiced accounts for the links between value dimensions and prejudice toward immigrants. We expected that those values that predispose people to express higher favorability toward immigrants (e.g., self-transcendence and openness values) may do so because they provide a guiding belief framework (e.g., believing in the importance of being tolerant toward immigrants) that spawns a more internalized and less external motivation to be non-prejudiced.

\section{Perceptions of Immigrant Values}

In addition to examining how individuals' own values relate to prejudice, the present research considered the influence of individuals' perceptions of immigrant values. In his original conception of the circumplex theory of values, Schwartz (1992) highlighted the importance of identifying perceptions of values held by individuals' own groups as well as perceptions of the values held by other groups. Nevertheless, examinations of the perceived values held by other groups, especially cultural groups, have so far been restricted in their focus. For instance, there is experimental evidence that people evaluate immigrants more positively when they are led to believe that the immigrants attach higher (versus lower) importance to positive values such as family, education, and freedom (Maio, Bell, \& Esses, 1996; Maio, Esses, \& Bell, 1994). Although this research supported a causal impact of immigrants' values on prejudice, it conflated effects of perceptions of values with presented extremes of value endorsement that are unlikely to reflect measured or naturally occurring perceptions of immigrant values. In contrast, the aim of the present research was to examine individuals' naturally occurring perceptions of immigrant values and how these relate to prejudice. To the best of our knowledge, only one project has examined such a link.

Schwartz et al. (1990) found that Israeli individuals allocated more resources to a German outgroup when they perceived them to hold higher self-transcendence values and lower conservation values. Similarly, German individuals allocated more resources to an Israeli 
outgroup when they perceived them as higher in self-transcendence values and lower in selfenhancement values. Hence, perceptions of higher self-transcendence values in outgroups may evoke lower prejudice.

The present research used polynomial regression analyses to examine how individuals' perceptions of immigrant values relate to prejudice. We extended previous scarce evidence on this link by testing a role for perceived values that is independent from individuals' own values. It was important to identify whether perceived values play a unique role in predicting prejudice, because perceived values are likely to be strongly infused by individuals' own values. Further, the present studies extended previous evidence by considering a range of novel immigrant groups.

\section{Value Dissimilarity}

The idea that dissimilarities with the outgroup lie at the heart of prejudice has a long history in psychological research. For instance, Rokeach's (Rokeach, Smith, \& Evans, 1960) belief congruence theory and Byrne's (1961; Byrne \& Wong, 1962) similarity-attraction theory suggested that prejudice results from perceiving dissimilarities between the self and the outgroup in terms of attitudes, beliefs, and values. Over the decades, researchers have amassed considerable experimental and correlational evidence supporting a link between prejudice and self-outgroup dissimilarities in attitudes and beliefs (e.g., Byrne \& Wong, 1962; Insko, Nacoste, \& Moe, 1983). Perceptions of value dissimilarity have been suggested to be a particularly important factor in driving prejudice. As Allport (1954) put it: "in a deep sense, we are the values that we hold, we cannot help but defend them with pride and affection, rejecting every group that opposes them" (p. 74).

Several studies have provided experimental support for the notion that self-outgroup value dissimilarity increases prejudice. For example, describing African Americans as having dissimilar rather than similar values when compared to oneself has been found to increase 
prejudice among White participants (e.g., Rokeach \& Mezei, 1966; Stein, Hardyck, \& Brewster Smith, 1965). However, as mentioned above, while such research supports the view that artificially high or low levels of value dissimilarity impact prejudice, it does not consider naturally occurring perceptions of value dissimilarities with the outgroup. The aim of the present research was to examine whether such dissimilarities between individuals' own values and their naturally occurring perceptions of the outgroup's values relate to prejudice against immigrants.

A few studies have examined this question. For instance, Haddock et al. (1993) found that individuals who perceive greater value dissimilarity between themselves and homosexuals are more prejudiced against them. Moreover, they found that value dissimilarities are greater among individuals higher in right-wing authoritarianism - a trait consistently linked with higher levels of prejudice (Altemeyer, 1988). Similarly, other studies have found that self-outgroup value dissimilarity predicts prejudice toward feminists and indigenous Chilean people as outgroups (Dunbar et al., 2000; O’Driscoll \& Feather, 1983). While this evidence generally provides support for the idea that self-outgroup value dissimilarity predicts more prejudice, there are issues and considerations suggesting that this relationship may often be more complex. First, this past research employed (absolute) difference scores or profile correlations to calculate value dissimilarity. As discussed above, such approaches may have overstated or misrepresented the role of value dissimilarities in predicting prejudice (Edwards, 1993, 1994, 2002; Griffin et al., 1999). Second, these previous studies have examined value dissimilarity without considering the influence of individuals' own and their perceived values. However, as we have seen in the comparison of Figures $2 \mathrm{a}$ and $2 \mathrm{~b}$, the nature of a dissimilarity effect can differ considerably depending on whether linear effects are present or absent. Hence, examining the complex interplay between these effects is crucial in interpreting dissimilarity effects on prejudice. 
Third, the notion that the role of value dissimilarities in predicting prejudice may be more nuanced is consistent with seminal perspectives suggesting that under certain circumstances dissimilarity may be associated with higher outgroup favorability. In particular, social identity theory (Tajfel \& Turner, 1979) argues that individuals tend to establish positive distinctiveness to an outgroup, or in other words, people like to believe that their ingroup is dissimilar to an outgroup. For the individual, seeing dissimilarity between groups helps to maintain a positive self-concept, promote social meaning, and reduce subjective uncertainty about group boundaries. Similarly, optimal distinctiveness theory (Brewer, 1991) suggests that individuals strive for an optimal balance between similarity and dissimilarity, and this is the case in both interpersonal and intergroup contexts (Leonardelli, Picket, \& Brewer, 2010). Interestingly, while social identity theory predicts that high intergroup similarity will be experienced as threatening a sense of uniqueness and should hence result in higher prejudice against the outgroup, self-categorization theory (Turner, Hogg, Oakes, Reicher, \& Wetherell, 1987) suggests that higher similarity should generally be associated with lower prejudice. According to a meta-analysis by Jetten, Spears, and Postmes (2004), both predictions may be true under different circumstances. For instance, when individuals were more identified with their ingroup, higher value similarity was linked with more prejudice, consistent with social identity theory, whereas when individuals were less identified, higher value dissimilarity was linked with more prejudice, consistent with selfcategorization theory. Together, this evidence supports the view that value dissimilarity effects on prejudice may be more complex than previously suggested.

Finally, prior examinations assessed value dissimilarity as a global index across value types and dimensions. However, this approach may have obscured the possibility that some types of values play a more important role in value dissimilarity effects on prejudice than others. Support for this view comes from evidence in organizational psychology indicating that effects of value dissimilarity differ depending on which types of values are considered 
(Abbott et al., 2005; Finegan, 2000). Similarly, social identity theory specifies that people will strive for positive distinctiveness against an outgroup on a dimension that is relevant and central to the intergroup context. This prediction suggests that value dissimilarity effects are more likely to emerge for values that individuals see as being more relevant to the particular immigration context. Looking at Schwartz's model, these values could be expected to include those that pertain to national security and the maintenance of existing norms and traditions (i.e., conservation values). For instance, dissimilarities in terms of valuing tradition or security may feel particularly threatening to some individuals, whereas dissimilarities in terms of valuing curiosity may be less important. There may also be other values that are seen as relevant to an immigration context (e.g., equality, authority; Schwartz et al., 1990). Nevertheless, given the lack of previous evidence on this topic, we had no specific expectations as to which values play a more important role in value dissimilarity effects. Instead, we aimed to explore the effects in an initial study and subsequently replicate these in further studies to establish reliably which value dimensions play a more important role in value dissimilarity effects on prejudice.

Overall, these considerations indicate that previous work may have overstated and simplified the role of value dissimilarity in predicting prejudice, and they support the view that the relationship between value dissimilarity and prejudice may depend on which value dimension is considered. Given this potential complexity, it is important to conceptually replicate previous work using an improved analytical approach, polynomial regression analyses.

\section{The Present Research}

The present research tested the role of values in prejudice against immigrants in a multi-faceted fashion, using polynomial regression analyses. The present research goes beyond previous work by testing whether value dimensions play a different role in value dissimilarity effects on prejudice. Further, by complementing these analyses with a 
mediational approach, we explored whether the more concrete motivation to be nonprejudiced can account for the link between own values and prejudice. We additionally sought to extend the previous scarce evidence on the link between perceptions of values and prejudice.

The present three studies examined these aims in a current immigration context with three concrete immigrant groups. Specifically, samples of non-Muslim British students were presented with Muslim immigrants (Study 1), or economic migrants and refugees (Studies 2 and 3) as target groups. There are several reasons for selecting these outgroup targets. First, studying specific immigrant groups as targets is vital in its own right and we know of no evidence examining the effects of value dissimilarity or perceptions of values on prejudice across specific immigrant groups. Second, the effects of values may depend on the particular immigrant group being studied. For instance, previous research has found that effects for perceived values and value dissimilarity differ between target groups (e.g., Schwarz et al., 1990). Hence, the selection of multiple target groups in the present research enabled us to explore whether the effects of values are specific to each group or whether they generalize.

All three of the present studies examined two outcome variables as indicators of prejudice: evaluations of immigrants and perceptions of symbolic threat from immigrants. Symbolic threat, as introduced by symbolic racism theory (Kinder \& Sears, 1981; McConahay, Hardee, \& Batts, 1981) and integrated threat theory (Stephan, Stephan, \& Oskamp, 2000; Stephan et al., 1999), involves seeing the outgroup as having dissimilar values that threaten the ingroup's worldviews. Although symbolic threat has generally been defined at the group level, Stephan and Renfro (2002) have suggested that symbolic threat can also occur at the individual level (Stephan \& Stephan, 2017). Moreover, previous work has often presented and used symbolic threat as an expression of prejudice (e.g., Pettigrew \& Mertens, 1995; Rohmann, Florack, \& Piontkowski, 2006; Vala, Pereira, \& Ramos, 2006). 
The present research generally concentrated on self-immigrant value dissimilarity, based on previous suggestions that individuals react more strongly to individual-level threats than group-level threats (Gaertner, Sedikides, Vevea, \& Iuzzini, 2002; Leonardelli, Pickett, \& Brewer, 2010). Nonetheless, in Study 3 we also explored how intergroup value dissimilarity relates to evaluations and symbolic threat, based on a literature that has theorized and found effects of intergroup value dissimilarity on prejudice that generally mirror those of selfoutgroup value dissimilarity (e.g., Schwartz et al., 1990; Stephan et al., 1999; Struch \& Schwartz, 1989).

For all three target groups, we simultaneously examined the independent effects of individuals' own values, perceived values of immigrants, and values dissimilarity on evaluations and symbolic threat in polynomial regression analyses. These analyses were complemented by mediation analyses linking individuals' own values and the prejudicerelated outcomes through the motivation to be non-prejudiced. Based on the literature reviewed above, we tested the following hypotheses:

(1) Individuals who prioritize self-transcendence values over self-enhancement values or openness values over conservation values would express lower prejudice toward immigrants.

(2) Individuals who perceive immigrants to hold higher self-transcendence values would express lower prejudice toward them. Given mixed past evidence, we were agnostic about relations on the conservation versus openness dimension.

(3) The link between own values and prejudice would be mediated by the motivation to be non-prejudiced.

(4) Individuals who perceive higher self-immigrant value dissimilarity on both value dimensions would express higher prejudice against immigrants (see Figure 4 for these hypotheses). 


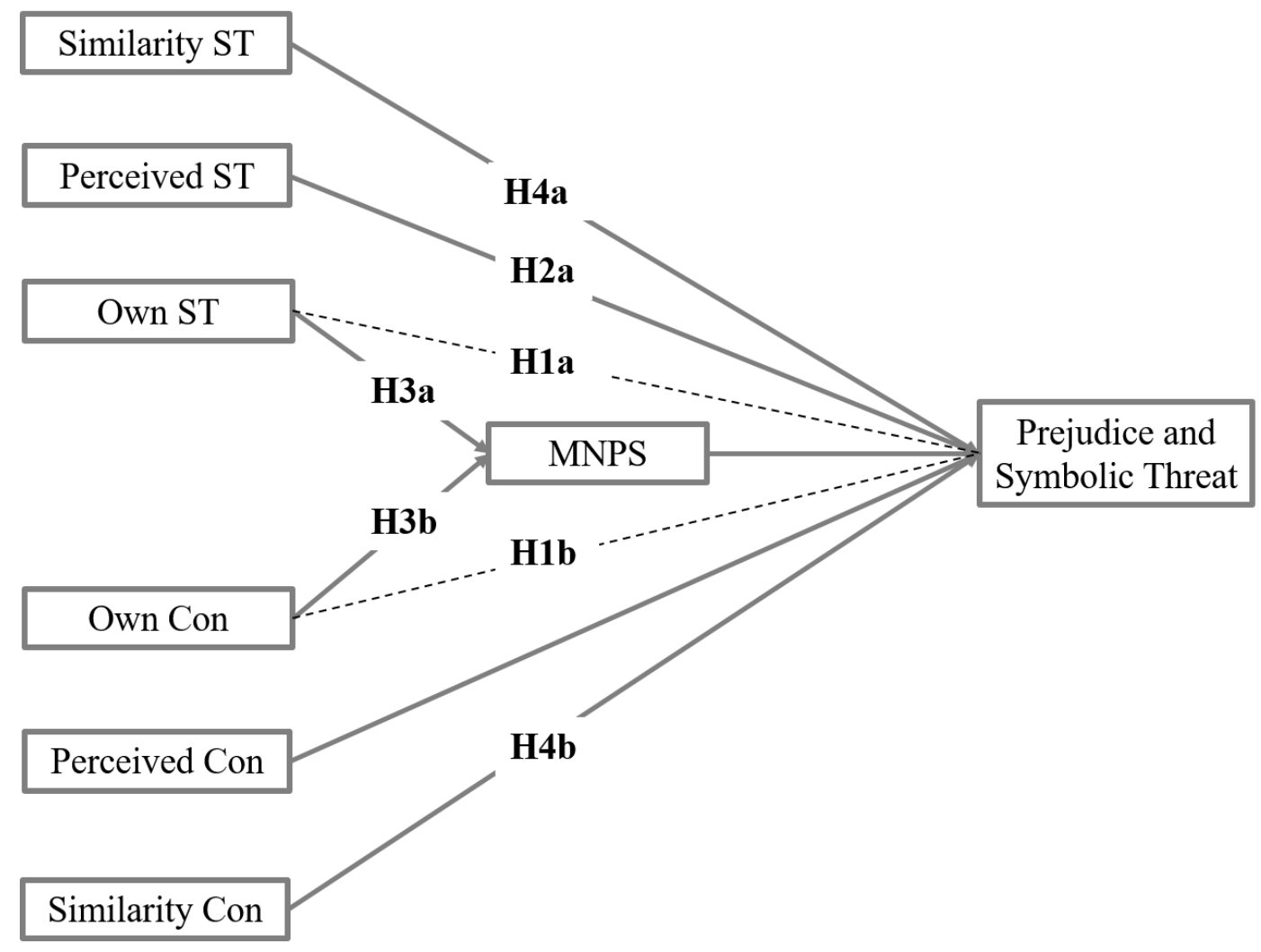

Figure 4. Hypotheses $(\mathrm{H} 1-\mathrm{H} 4)$ in the present study. ST=self-transcendence versus selfenhancement values. Con=conservation versus openness values. MNPS=motivation to be non-prejudiced. Own=individuals' values. Perceived=perceptions of immigrant values.

\section{Study 1}

Muslim immigrants were the target group in Study 1. Muslim immigrants are the largest religious outgroup in the UK (Office for National Statistics, 2012) and they are often the targets of negative views and feelings (e.g., Strabac \& Listhaug, 2008; Velasco González, Verkuyten, Weesie, \& Poppe, 2008; Wolf, Maio, Karremans, \& Leygue, 2017), which have grown as a result of terrorist attacks (Dunwoody \& McFarland, 2017). Consistent with our expectations for the effects of individuals' own values, there is tentative empirical evidence suggesting that people higher in self-transcendence values and lower in self-enhancement values show lower prejudice toward Muslim immigrants (Saroglou et al., 2009). 


\section{Method}

Power analyses. Previous research testing the link between value dissimilarity and prejudice has generally found relatively large effect sizes between $\beta=.42$ and $\beta=.45$ (Dunbar et al., 2000; Haddock et al., 1993; Struch \& Schwartz, 1989). However, there is also evidence of weaker effects between $\beta=.00$ and $\beta=.21$ (Schwartz et al., 1990), and importantly, we expected the current polynomial regression approach to provide a more conservative estimate than previous research. Hence, we based the power analysis on a medium effect size $(\beta=.30)$, which we reasoned would reflect a theoretically and practically meaningful value dissimilarity effect.

Using G*Power (Faul, Erdfelder, Lang, \& Buchner, 2007), the required sample size was 82 participants for a two-tailed linear regression analysis, a medium effect, a power of .80 , and an alpha level of .05 . This power calculation is consistent with Barranti et al.'s (2017) recommended sample size of 77 participants to detect a medium effect in polynomial regression analyses. We recruited additional participants in order to meet this sample size requirement after participant exclusion.

Participants and procedure. Ninety-four participants took part in an online study at [anonymized for review]. Because we aimed to investigate the perception of Muslim immigrants as an out-group in the UK, all reported analyses are restricted to non-Muslim British participants, but non-British and Muslim participants were allowed to take part for ethical reasons. We retained 84 participants (76 women; $18-24$ years of age, $M_{\text {age }}=18.55$ ), 78 of whom indicated the UK as their birthplace. When asked about their ethnicity, 80 participants identified as White European, two as Asian, and two as 'Other'. Fifty-seven participants were non-religious, 22 were of Christian faith, and five indicated 'Other'.

Participants first completed a pre-test assessing their own values. Approximately three weeks later, they completed additional measures assessing their perceptions of Muslim immigrants' values, symbolic threat, evaluations, and motivation. Participants completed the 
survey in October 2015 in approximately 20 minutes and were compensated with course credit. All three studies reported here are consistent with APA ethical standards in the treatment of human subjects and received ethical clearance from the School of Psychology at [anonymized for review].

\section{Measures.}

Pre-test measure of values. Participants' own values were measured with the 56-item version of the Schwartz Value Survey (SVS; Schwartz, 1992). The SVS measures two value dimensions: self-transcendence $(\alpha=.85)$ versus self-enhancement $(\alpha=.83)$ and conservation $(\alpha=.80)$ versus openness to change $(\alpha=.81)$. Example items include "equality - equal opportunity for all”, "social power - control over others, dominance" on the selftranscendence versus self-enhancement dimension, and "social order (stability of society)", "freedom (freedom of action and thought)" on the conservation versus openness dimension. Participants indicated the personal importance of the value items on a scale from -1 (opposed to their values) and 0 (not important) to 6 (very important) and 7 (of supreme importance).

To ensure that the data conformed to the hypothesized value structure of Schwartz's model, enabling us to compute value dimension scores, we examined the Tucker's congruence coefficient as an index of the goodness of fit to this structure. Tucker's congruence coefficient was derived from multidimensional scaling analyses using the theorybased starting configurations provided by Schwartz's model (Bilsky, Janis, \& Schwartz, 2011). This starting configuration assigns every value item its place within the hypothesized value structure. Based on recommendations that coefficients above .95 indicate good fit (Lorenzo-Seva \& ten Berge, 2006), the data indicated an excellent fit to this hypothesized structure (.997). Accordingly, we aggregated participants' responses, such that higher scores on the dimensions indicate higher importance of self-transcendence values than selfenhancement values, and higher importance of conservation values than of openness values (Ros, Schwartz, \& Surkiss, 1999; Schwartz 1994). 
Perceived values of Muslim immigrants. Participants read a short paragraph containing background information about Muslim immigration in the UK (e.g., percentage of UK population with Muslim background). Next, participants completed a similar 56-item SVS, with the difference that participants were now asked "According to you, which values are important to typical Muslim immigrants as guiding principles in their life, and which values are less important to them?". The dimensions self-transcendence $(\alpha=.92)$ versus selfenhancement ( $\alpha=.80)$, and conservation $(\alpha=.80)$ versus openness $(\alpha=.87)$ were internally consistent and were aggregated in the same way as participants' values. The Tucker's congruence coefficient indicated an excellent fit (.998).

Perceptions of symbolic threat from Muslim immigrants. Symbolic threat from Muslim immigrants (Stephan et al., 1999) was measured with seven items (e.g., "The values and beliefs of Muslim immigrants regarding moral issues are not compatible with the beliefs and values of most British people."), to which we added one item, "Because of Muslim immigrants I feel like a stranger in my own country". ${ }^{1}$ Participants responded to these eight items in a randomized order and on a scale from 1 (strongly disagree) to 10 (strongly agree). Items loaded on one reliable $(\alpha=.86)$ factor. The scores on the items were aggregated such that higher scores indicate higher perceptions of threat. ${ }^{2}$

Evaluations of Muslim immigrants. Next, participants indicated to what extent they support a governmental policy to attract Muslim immigrants and to what extent they would be willing to sign a petition to stop this policy. These two questions were answered on scales from 1 (not at all) to 7 (very much). In addition, participants indicated their favorability toward Muslim immigrants using a 101-point evaluation thermometer from $0^{\circ}$ (extremely unfavorable) to $100^{\circ}$ (extremely favorable; Haddock et al., 1993). Finally, participants indicated how much they like and trust a typical Muslim immigrant on a scale from 1 (not at all) to 7 (very much). These five evaluation measures loaded on one common factor and were 
hence aggregated to compute a mean evaluation score $(\alpha=.88)$, with higher scores indicating higher favorability. ${ }^{3}$

Motivation to be non-prejudiced. The Motivation to be Non-Prejudiced Scale (MNPS; Legault et al., 2007) presents 24 reasons for being non-prejudiced in a randomized order. Participants indicated to what extent each item corresponds to their ultimate reasons for avoiding prejudice against Muslim immigrants; items were paired with a scale from 1 (does not correspond at all) to 7 (corresponds exactly). ${ }^{4}$ This scale was developed to represent the six motivational dimensions of Self-Determination Theory (Deci \& Ryan, 2000). Hence, the reasons differ in the extent to which they reflect self-determination or autonomy in avoiding prejudice. To represent the degree of self-determination in avoiding prejudice, we followed Legault et al.'s (2007) procedure to compute a single score that assigns a weight to each dimension according to its level of self-determination. Higher values on this score indicate stronger self-regulated motivation to avoid prejudice $(\alpha=.79) .{ }^{5,6}$

\section{Results}

Analytic approach. Polynomial regression analyses were used to examine the data in the statistical program R (version 3.5.1; R Core Team, 2018). We also produced response surface analyses (RSA; R package 'RSA'; Schönbrodt \& Humberg, 2018) plots to allow for visual inspection of the complex interplay between the linear, quadratic, and interactive effects. $^{7}$

We examined these effects in polynomial regression analyses for both value dimensions (self-transcendence vs. self-enhancement and conservation vs openness) and on both outcomes (evaluation and symbolic threat) simultaneously. Significant multivariate effects were broken down to the univariate tests to examine the directionality of the effects on each outcome separately. For all univariate tests, a Bonferroni-adjusted alpha level of .025 was applied to account for the dual comparisons. We produced RSA plots for each outcome separately, because we reasoned that illustrating effects on evaluation and symbolic threat 
would be more meaningful and comprehensible than on an aggregate favorability index. Following recommendations from Barranti et al. (2017) and Humberg et al. (2018), we verified the occurrence of similarity between own and perceived value scores and of dissimilarity in either direction between own and perceived value scores in our data (i.e., people whose values are higher than how they perceive immigrant values and people whose values are lower than how they perceive immigrant values). In addition, we verified that own and perceived values were not multicollinear, and we ensured that all predictors were centered around the scale midpoint. We focused on the interaction term as an indicator of a possible dissimilarity effect and evaluated it in the light of the other present effects. Finally, we examined whether effects of participants' values on the outcomes were mediated by the motivation to be non-prejudiced (MNPS).

Main analysis. Using the ' $\mathrm{lm}$ ' function in $\mathrm{R}$, we regressed evaluation and perceived symbolic threat from Muslim immigrants onto the four main effects (i.e., participants' own and perceived self-transcendence vs self-enhancement and conservation vs openness values) in the first step, their two interaction terms in the second step, and their four quadratic terms in the third step. To conduct the multivariate tests, we used the 'Anova' function in the 'car' package (Fox \& Weisberg, 2011). The multivariate tests for participants' own and perceived values on the self-transcendence versus self-enhancement value dimension were significant, $F(2,78)=8.48, p<.001 ; F(2,78)=28.01, p<.001$, respectively. The univariate tests showed that Muslim immigrants were evaluated more favorably when participants were higher in selftranscendence values, $b=0.24, S E=0.08, \beta=0.27, p=.005$ (evaluation), $b=-0.47, S E=0.11$, $\beta=-0.34, p<.001$ (symbolic threat), and when Muslim immigrants were viewed as being higher in self-transcendence values, $b=0.38, S E=0.07, \beta=0.50, p<.001$ (evaluation), $b=-0.70$, $S E=0.09, \beta=-0.60, p<.001$ (symbolic threat).

The multivariate interaction term, $F(2,76)=0.30, p=.74$, and the multivariate quadratic term of participants' own values, $F(2,72)=1.80, p=.17$, were non-significant, suggesting an 
absence of a dissimilarity effect on the self-transcendence versus self-enhancement dimension. The quadratic term of participants' perceived values on the self-transcendence versus self-enhancement dimension was significant, $F(2,72)=3.54, p=.034$, indicating an inverted U-shaped relationship between perceived values and the outcomes. That is, favorability toward Muslim immigrants was lower at the extreme ends of self-transcendence or self-enhancement values, $b=-0.07, S E=0.03, \beta=-0.21, p=.023$ (evaluation), $b=0.09$, $S E=0.04, \beta=0.19, p=.019$ (symbolic threat). The RSA plots in Figure 5 illustrate the linear effects of participants' own and perceived values on evaluation and symbolic threat, and a negative quadratic effect of perceived values, in the absence of a dissimilarity effect on the self-transcendence versus self-enhancement dimension.

a

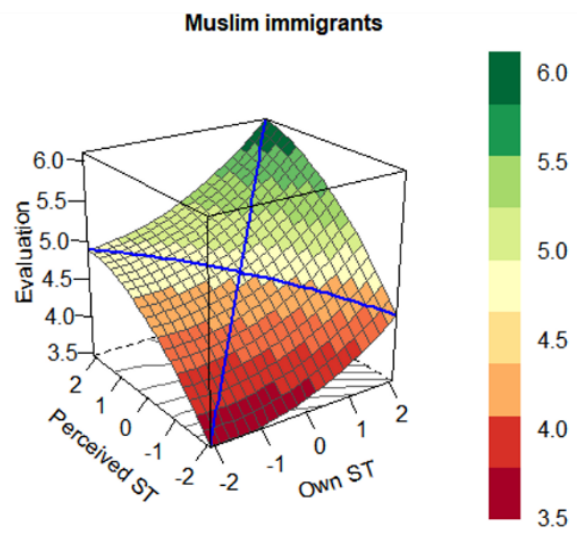

b

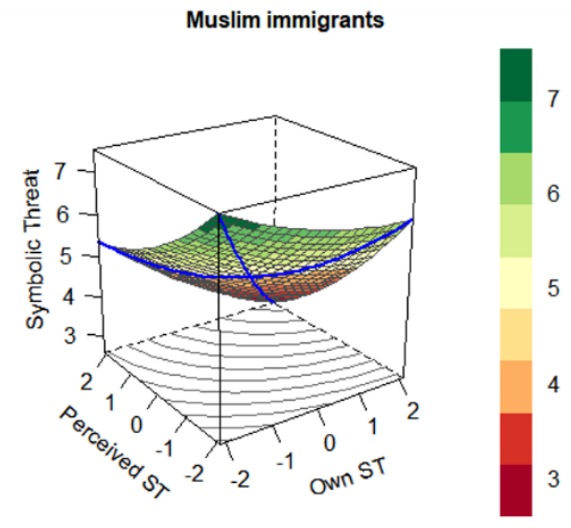

Figure 5. Study 1: Response surface analyses plots illustrating effects of own and perceived self-transcendence versus self-enhancement values (“ST”) on evaluations and symbolic threat from Muslim immigrants. Higher own and perceived selftranscendence values predicted more favorability toward Muslim immigrants on both outcomes. There were no indications of dissimilarity effects.

Concerning the conservation versus openness values dimension, there were no effects of participants' own values, $F(2,78)=0.11, p=.90$, or their perceived values, $F(2,78)=0.09$, $p=.91$. Similarly, the quadratic terms of participants' own values, $F(2,72)=0.15, p=.86$, and their perceived values, $F(2,72)=0.19, p=.83$, were non-significant. However, the interaction 
was significant, $F(2,76)=3.74, p<.028$. The univariate test for symbolic threat was significant, $b=-0.33, S E=0.12, \beta=-0.22, p=.008$, whereas the test for evaluation was non-significant after correcting for the multiple comparison, but pointed in the expected direction, $b=0.18$, $S E=0.09, \beta=0.19, p=.050$. To break this interaction down, we first computed an average across evaluation and symbolic threat and conducted a simple slopes analysis. This analysis indicated that when Muslim immigrants were perceived to be lower in conservation values $(-1 S D)$, participants higher in conservation values evaluated them less favorably, $b=-0.28$, $S E=0.12,95 \%$ CI $[-0.53,-0.10]$, suggesting a dissimilarity effect. Put differently, when Muslim immigrants were perceived to be higher in openness values, participants higher in openness values evaluated them more favorably. In contrast, at higher perceived conservation values $(+1 S D)$, there was no effect of own values on both outcomes combined, $b=0.12$, $S E=0.10,95 \%$ CI $[-0.08,0.31]$.

Figure 6 illustrates this dissimilarity effect on the conservation versus openness value dimension, in the absence of linear and quadratic effects. As expected, favorability was lowest at a point of maximum dissimilarity between own and perceived values (i.e., at -2 on "perceived Con" or higher perceived openness values and +2 on "own Con" or higher own conservation values) and highest at a point of maximum similarity (i.e., at -2 on "perceived Con" or higher perceived openness values and -2 on "own Con" or higher own openness values). On the opposite side (i.e., at +2 on the "perceived Con" axis), the points of maximum dissimilarity and similarity did not differ significantly from each other but pointed in the expected direction as can be seen in the figure. The figure also illustrates that similarity between own and perceived values was linked to more positivity at the extreme ends of the predictors (i.e., at $-2 /-2$ and $+2 /+2$ ) and less so at midrange levels (e.g., at $0 / 0$ ), due to the absence of negative quadratic effects. The absence of linear and quadratic effects on this value dimension indicates that the surface was not askew or shifted along the axes of own values or perceived values. These results suggest a "strict" value dissimilarity effect 
(Humberg et al., 2018), but only at extreme values of own and perceived values. The results for the univariate regressions are shown in Tables 1 and 2.

a

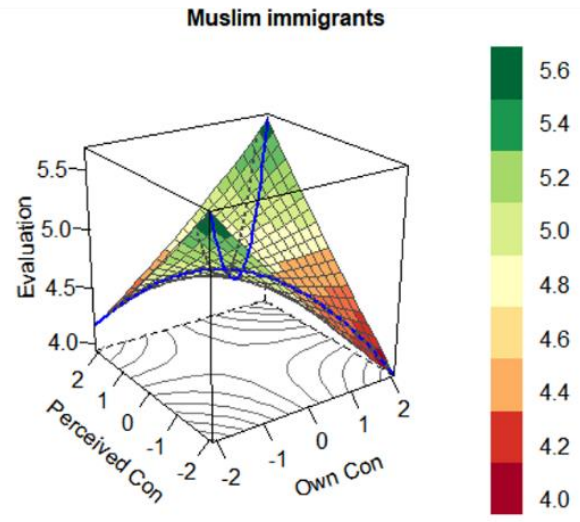

b

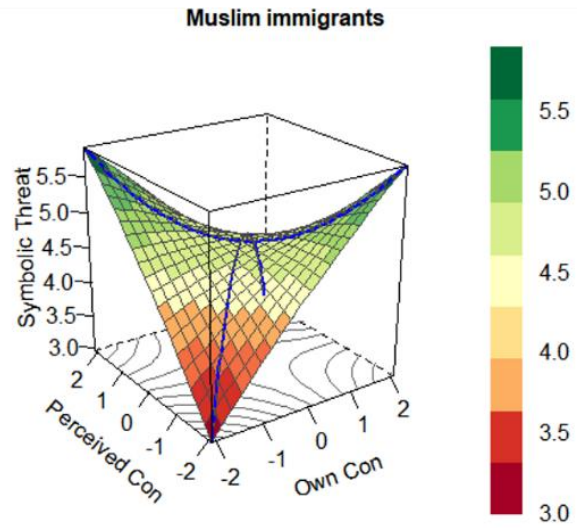

Figure 6. Study 1: Response surface analyses plots illustrating a tendency for a dissimilarity effect between own and perceived conservation versus openness values ("Con") on evaluations and symbolic threat from Muslim immigrants. Favorability was lower when individuals who held higher conservation values perceived Muslim immigrants to value openness more (i.e., at -2 "own Con" and +2 "perceived Con"). The linear effects of own conservation values and perceived conservation values were non-significant.

Mediation by motivation to be non-prejudiced. We tested whether the motivation to be non-prejudiced (MNPS) mediated the associations between own values and the outcomes. This mediation model was built in structural equation modelling (SEM) using the 'lavaan' package (Rosseel, 2012) in R with 5000 bootstraps. A latent factor favorability was entered, on which both evaluation and symbolic threat toward Muslim immigrants loaded. Further, participants' values on both dimensions were entered as exogenous variables, with respective indirect paths going through MNPS. We also included direct paths for perceived values on the respective value dimensions to control for their variance. Figure 7 shows that MNPS mediated the effect of own self-transcendence versus self-enhancement values on favorability toward Muslim immigrants. The effect of own self-transcendence versus self- 
enhancement values was reduced but remained significant after controlling for MNPS.

MNPS also mediated the effects of own conservation versus openness values on favorability toward Muslim immigrants. The effect of own conservation versus openness values remained non-significant after controlling for MNPS. See Table 3 for the descriptive statistics and correlations among all study variables.

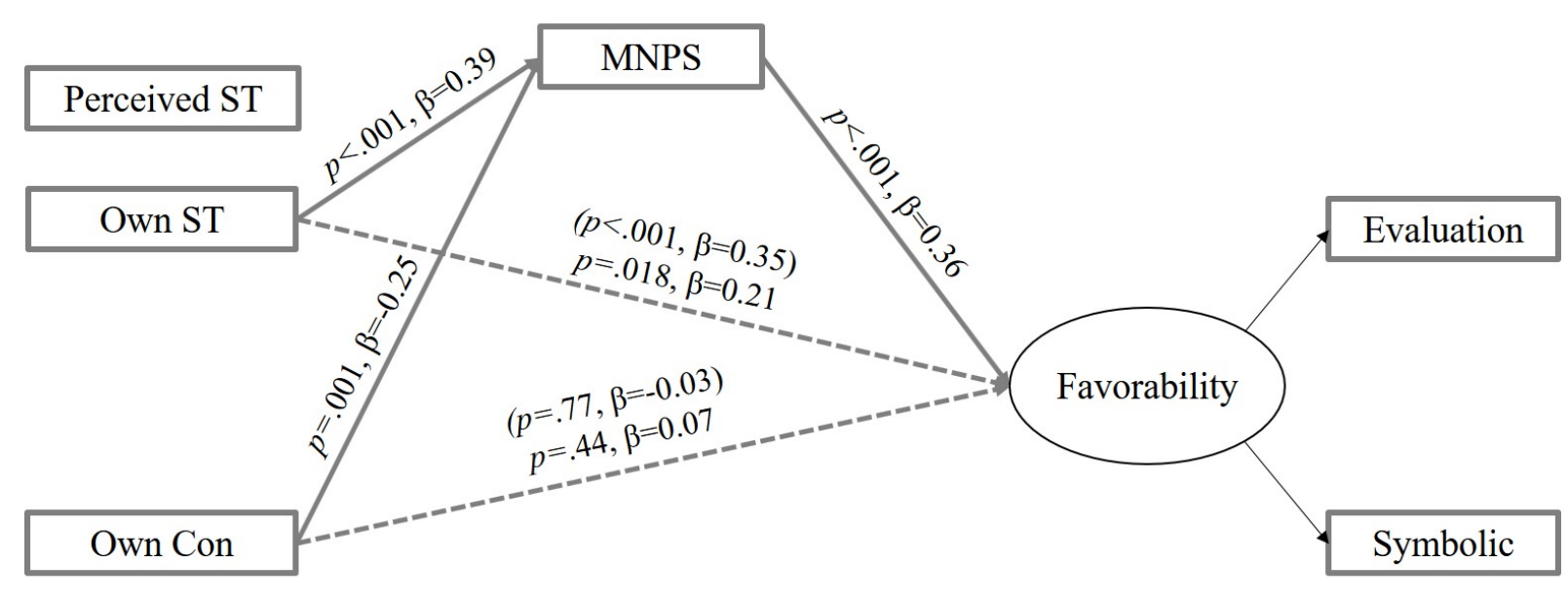

Perceived Con

$\underline{\text { Indirect effect }}$

ST: $b=0.11, S E=0.04$, CI 95\% [0.03, 0.19]

CO: $b=-0.06, S E=0.03$, CI 95\% [-0.12, -0.01$]$

Figure 7. Study 1: Motivation to be non-prejudiced (MNPS) mediated the effects of own self-transcendence versus self-enhancement values (“ST") and of own conservation versus openness values (“Con”) on evaluation and symbolic threat regarding Muslim immigrants. Both mediational paths controlled for the influence of perceived values.

\section{Discussion}

Study 1 found that prejudice toward Muslim immigrants was lower among individuals who held higher self-transcendence values and who perceived Muslim immigrants to hold higher self-transcendence values, supporting our hypotheses (H1A \& H2A) concerning this value dimension. As expected, this effect of own values was mediated by the motivation to be non-prejudiced (H3A), indicating that self-transcendent values predicted a more internalized motivation to be non-prejudiced, which in turn related to more positivity toward 
Muslim immigrants. In contrast, on the conservation versus openness dimension, the results generally indicated that individuals' own and perceived values were not associated with outcomes, contrary to our expectations (H1B). Interestingly, there was nevertheless a significant indirect effect on this values dimension $(\mathrm{H} 3 \mathrm{~B})$, such that individuals with higher conservation values had a more external motivation to be non-prejudiced, which in turn predicted less favorability toward Muslim immigrants.

Study 1 found evidence of a dissimilarity effect on the conservation versus openness dimension predicting symbolic threat from Muslim immigrants (H4B). This dissimilarity effect indicated that, when Muslim immigrants were perceived as higher in openness values (and lower in conservation values), individuals higher in conservation values reported more symbolic threat from Muslim immigrants. That is, someone who attaches more importance to such values as self-discipline or preserving traditions (conservation values) feels more threatened by Muslim immigrants perceived as valuing independence and an exciting life (openness values). The flip side of this dissimilarity effect is a similarity effect for openness values. That is, individuals higher in openness values were more favorable toward Muslim immigrants when they saw them as higher in openness values, and this similarity effect tended to be stronger at extreme levels of own and perceived values than at midrange levels. In contrast, there was no effect when Muslim immigrants were perceived to be higher in conservation values. In addition, there was no evidence for a dissimilarity effect on the selftranscendence versus self-enhancement value dimension (H4A).

Study 1 provides the first test of value dissimilarity effects on prejudice using polynomial regression analyses. This analytical approach does not conceal or distort information as happens in previously used methods, and hence provides a statistically more valid test of value dissimilarity effects (Barranti et al., 2017; Edwards, 2002; Humberg et al., 2018). While previous research consistently found that higher value dissimilarity uniformly 
predicts more prejudice (e.g., Dunbar et al., 2000; Haddock et al., 1993), Study 1 obtained nuanced effects that are consistent with the broader prejudice literature.

On the one hand, self-categorization theory (Turner et al., 1987), belief congruence theory (Rokeach et al., 1960), and similarity-attraction theory (Byrne, 1961; Byrne \& Wong, 1962) suggest that higher dissimilarity should generally predict higher prejudice. On the other hand, social identity theory (Tajfel \& Turner, 1979) and optimal distinctiveness theory (Brewer, 1991) predict that perceiving oneself or one's ingroup as too similar to others or other groups can threaten one's or the ingroup's sense of uniqueness. Together, these competing perspectives may explain the non-significant findings obtained when Muslim immigrants were perceived to be higher in conservation values, self-transcendence values, and self-enhancement values. That is, although higher value dissimilarity may have generally predicted higher prejudice, this association was masked because very high similarity was linked with perceptions of threat. In contrast, among individuals higher in openness values, there is evidence that high value similarity is less threatening, which may explain the occurrence of the value dissimilarity effect on this value dimension. Specifically, those higher in openness values have been found to be less identified with their national ingroup (Roccas, Schwartz, \& Amit, 2010), and in turn, a meta-analysis by Jetten et al. (2004) showed that less identified individuals experienced lower similarity threat and accordingly revealed a uniform effect linking higher dissimilarities to higher prejudice. It is noteworthy that this meta-analysis by Jetten et al. also highlighted the conflicting predictions from social identity theory and self-categorization theory and found that, depending on the circumstances (i.e., high vs low identifiers, trait ratings measure vs reward allocation measure), dissimilarity effects can emerge that are in line with either of these predictions. Hence, the present research may indicate that dissimilarity effects are also more or less in line with either of these predictions depending on which particular value dimension is considered. 
The notion that individuals who value openness are less threatened by high similarity with immigrants is compelling when considering that openness values involve attaching importance to such principles as curiosity, an exciting life, or freedom. Hence, for these individuals, immigrants who also value openness may be seen as likely to satisfy their thirst for curiosity. Similarly, it is not surprising that dissimilarity effects arose for individuals' own conservation values, which involve attaching importance to such principles as social order, tradition, security. For these individuals, immigrant groups with opposing values such as independence, freedom, and an exciting life may be particularly likely to be perceived as threatening one's worldview and way of life. Overall, the present findings suggest that previous assertions that higher value dissimilarity generally predicts more prejudice (e.g., Dunbar et al., 2000; Rokeach et al., 1960) only apply when immigrants are believed to value openness more.

In sum, the polynomial regression analyses employed in Study 1, together with a new focus on value dimensions, reveals aspects of value dissimilarity effects that are likely to have been masked in previous examinations of such effects. By doing so, the findings extend previous evidence and theoretical perspectives linking value dissimilarity uniformly to higher prejudice (e.g., Dunbar et al., 2000; Haddock et al., 1993; Rokeach, 1960), but they are in line with a broader literature that suggests a more complex pattern for dissimilarity effects (Brewer, 1991; Jetten et al., 2004; Tajfel \& Turner, 1979; Turner et al., 1987). The results showed an effect of perceived value dissimilarity on prejudice, but only for dissimilarities with Muslim immigrants' openness values. At the same time, prejudice was reduced among individuals who expressed higher self-transcendence values or perceived higher selftranscendence values in Muslim immigrants. Thus, prejudice was linked to values in a multifaceted and complex manner. 


\section{Study 2}

Study 1 considered a religious group that is a prevalent immigrant group in the nation where the research was conducted. In Study 2, we tested whether our findings generalize to two additional immigrant groups which are salient in the UK and are often portrayed in the media (e.g., Kingsley, 2015): economic migrants and refugees. That is, participants evaluated immigrants twice: once as economic migrants coming to the UK to seek work and once as refugees coming to the UK to seek asylum. According to a YouGov poll, British respondents generally responded negatively toward both of these immigrant groups, with only a small minority supporting more admissions into the UK (YouGov, 2015; see also BBC, 2016). Similarly, there is robust evidence of prejudice toward economic migrants (e.g., Quillian, 1995; Verkuyten, 2004), and refugees (e.g., Esses, Veenvliet, Hodson, \& Mihic, 2008; Lazarev \& Sharma, 2015).

A key consideration is that refugees and economic migrants may differ in how they are perceived; for instance, refugees may be regarded as less responsible for their situation and therefore more deserving of help. These differences in perception may cause individuals' values, and especially their self-transcendence values (which entail sympathy toward people in need), to relate more strongly to evaluations of refugees than economic migrants. The inclusion of both immigrant groups enabled us to test whether values relate differently to evaluations of the groups or whether they generalize. ${ }^{8}$ Study 2 explored this possibility in addition to testing our main research aims carried over from Study 1.

\section{Method}

Participants and procedure. As in Study 1, we required 82 participants to detect a medium effect with a power of .80 . We again recruited additional participants to meet these requirements after participant exclusion. One-hundred and twenty-two participants took part in an online study at [anonymized for review]. Consistent with Study 1's exclusion criteria, we restricted all reported analyses to the 105 non-Muslim British participants (95 women, 10 
men; $18-26$ years of age, $M_{\text {age }}=19.42$ ). Of the remaining participants, 99 entered the UK as their birthplace. One hundred participants identified as White European, two as Asian, and three indicated 'Other' as their ethnicity. Seventy-three participants were non-religious, 29 of Christian faith, and three participants indicated 'Other' as their religion. Participants completed the survey in November 2015 in approximately 20 minutes and were compensated with course credit.

\section{Procedure and measures.}

Framing of immigrants. Participants evaluated immigrants that were either framed as refugees or as economic migrants. In the framing of immigrants as refugees [or, as economic migrants], participants were asked to think about immigrants who come to the UK to seek asylum [for economic reasons]. They were instructed "for the following questionnaires, please keep in mind those immigrants who are generally refugees [generally seeking to improve their living standards] in the UK. These immigrants often come to the UK because they are fleeing from persecution and personal danger in their home country (e.g., Syria) [because the living condition in their home country (e.g., Jordan) is poor]". Participants were presented with both framings of immigrants in a counterbalanced order.

Perceived values of immigrants. After framing immigrants as refugees or economic migrants, we assessed participants' perceived values of the respective immigrant group using the Short Schwartz Value Survey (SSVS; Lindeman \& Verkasalo, 2005). The SSVS measures values by asking participants to rate the importance of Schwartz's ten superordinate value types as life-guiding principles. Participants are presented with the ten value types, followed by the corresponding original SVS value items in brackets, for example, "Power (social power, authority, wealth)". Participants rated which values they perceived as important to the respective immigrant group on a scale from -1 (opposed to their values) and 0 (not important) to 4 (very important) and 5 (of supreme importance). Individuals' scores on the value dimensions self-transcendence versus self-enhancement and conservation versus 
openness were computed by applying Lindeman and Verkasalo's (2005) weightings for each value type. These weightings were developed using multidimensional scaling. To arrive at the value dimension scores, we weighted each value type and aggregated these weighted value types for each value dimension separately. The Tucker's congruence coefficients indicated a good fit for both measures (economic migrants: .998; refugees: .990), enabling us to perform these transformations.

Symbolic threat and evaluations. Perceptions of symbolic threat from immigrants (economic migrants: $\alpha=.84$; refugees: $\alpha=.82$ ) and evaluations (economic migrants: $\alpha=.86$; refugees: $\alpha=.83$ ) were measured as in Study 1, except that instead of referring to Muslim immigrants, we asked participants to keep the previous description of immigrants in mind.

Motivation to be non-prejudiced. After evaluating the two immigrant groups, participants completed the MNPS $(\alpha=.78)$ as in Study 1, indicating their reasons for trying to be unprejudiced toward immigrants in general.

Own values. Subsequently, we measured participants' values with the SSVS, in which participants rated the importance of each value type as a guiding principle in their own life. Participants' values were weighted in the same way as described above, resulting in the two value dimensions self-transcendence versus self-enhancement and conservation versus openness. The Tucker's congruence coefficient indicated a good fit for own values $(.997) \cdot{ }^{8,9,10}$

\section{Results}

Preliminary analyses. First, we tested whether the effects of values on favorability showed different patterns for the target groups refugees and economic migrants. To do so, we created a SEM model as shown in Figure 8, with two latent factors, favorability toward refugees and economic migrants, as the endogenous variables, and all polynomial regression terms of both value dimensions as the exogenous variables relating to the respective latent factor. Evaluation and symbolic threat were set to load on each latent factor. In a constrained 
model, we set equality constraints for each regression term between target groups. For instance, the regression weight for participants' own self-transcendence versus selfenhancement values on the latent factor was fixed to be equal between refugees and economic migrants. This constrained model was compared to a free model, where all regression weights were estimated as free parameters.
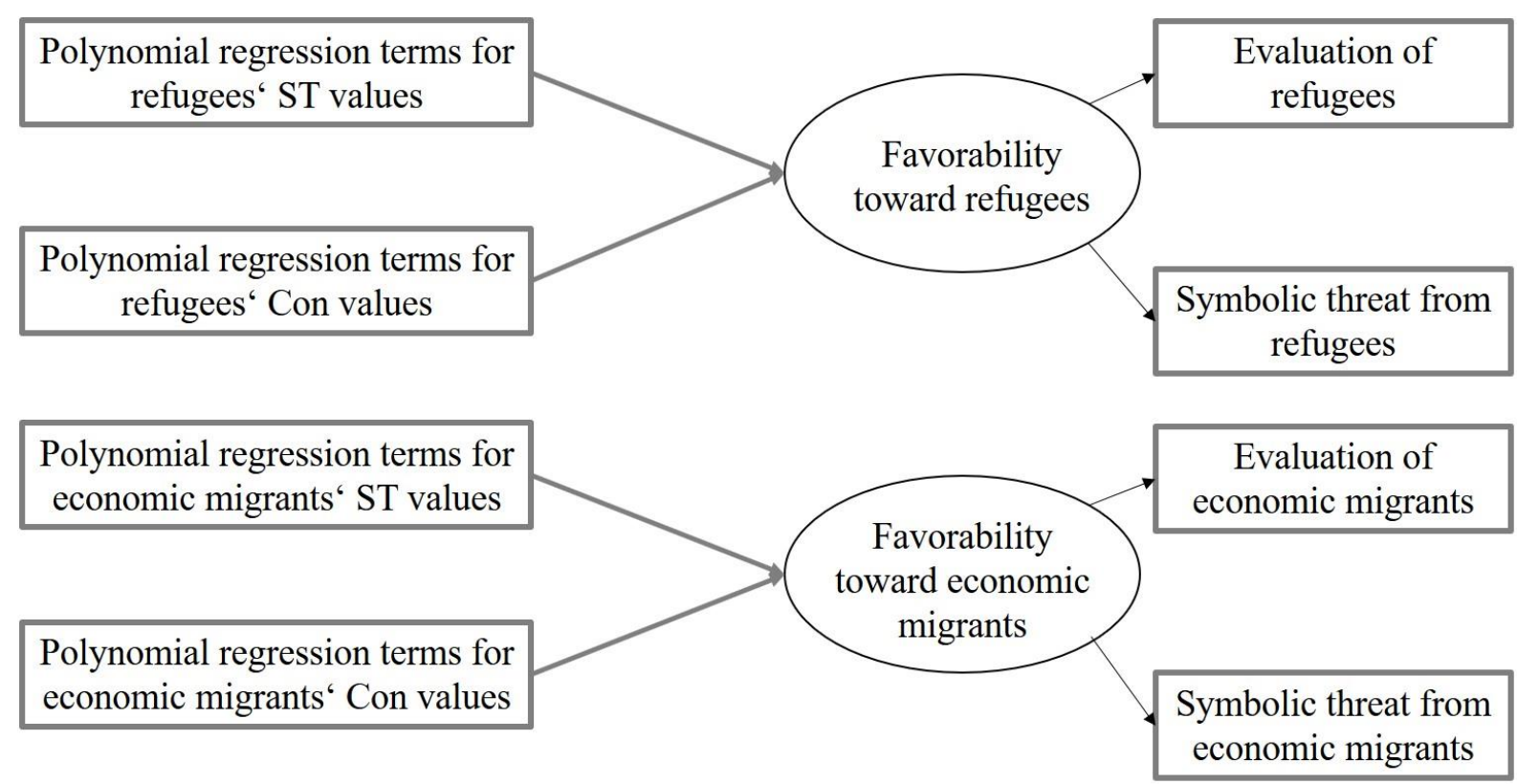

Figure 8. Study 2: Structural equation model to test whether effects the effects of values on favorability differed between the target groups: refugees and economic migrants. A constrained model, where each regression term was constrained to be equal between target groups, was compared to a free model. ST = self-transcendence versus self-enhancement values; Con $=$ own conservation versus openness values .

The constrained model showed better model fit, $\chi^{2}(55)=105.80, \mathrm{AIC}=1020.22$, $\mathrm{BIC}=1070.64$, than the free model, $\chi^{2}(45)=90.95, \mathrm{AIC}=1025.37, \mathrm{BIC}=1102.34$. To confirm this finding in regression analyses, we tested for all possible interactions of each regression term with target group. The only differential effect between target groups emerged for the interaction term between own and perceived conservation values, $t(324.89)=2.46, p=.014$. None of the other interactions reached significance. Hence, the preliminary analyses indicate 
that the pattern of effects generally does not differ between the target groups, with the exception of the interaction term between own and perceived conservation values. We therefore conducted all analyses across refugees and economic migrants, and additionally examined the interaction between own and perceived conservation versus openness values for each target group separately.

Main analysis. To account for the multivariate and repeated nature of our measures, the data were transformed into a long format such that each participant had four observations pertaining to each of the two target groups and each of the two outcomes. We analyzed the data in a linear mixed effects model using the 'lme4' package (Bates, Maechler, Bolker, \& Walker, 2015) and the 'lmer' function in R. The outcomes for both target groups were regressed on participants' own and perceived values in the first step, their interaction term in the second step, and their quadratic terms in the third step. This analysis included random intercepts for participants, target group, and outcome variable. Results showed that the effects of participants' own and perceived values on the self-transcendence versus selfenhancement dimension were significant, $t(102.87)=3.54, p<.001 ; t(378.86)=5.84, p<.001$, respectively. In particular, the immigrant groups were evaluated more favorably when participants were higher in self-transcendence values, $b=0.28, S E=0.09, \beta=0.24, p=.002$ (evaluation), $b=-0.47, S E=0.14, \beta=-0.28, p=.001$ (symbolic threat), and when they perceived the immigrant groups as being higher in self-transcendence values, $b=0.27, S E=0.04, \beta=0.36$, $p<.001$ (evaluation), $b=-0.22, S E=0.05, \beta=-0.20, p<.001$ (symbolic threat). The interaction term, $t(389.13)=1.52, p=.13$, and the quadratic terms of participants' values, $t(102.42)=-0.93$, $p=.36$, and their perceived values, $t(381.85)=-1.60, p=.11$, were not significant, again suggesting an absence of a dissimilarity effect on this values dimension. The RSA plots in Figure 9 illustrate these linear effects of own and perceived self-transcendence versus selfenhancement values, in the absence of dissimilarity effects. 


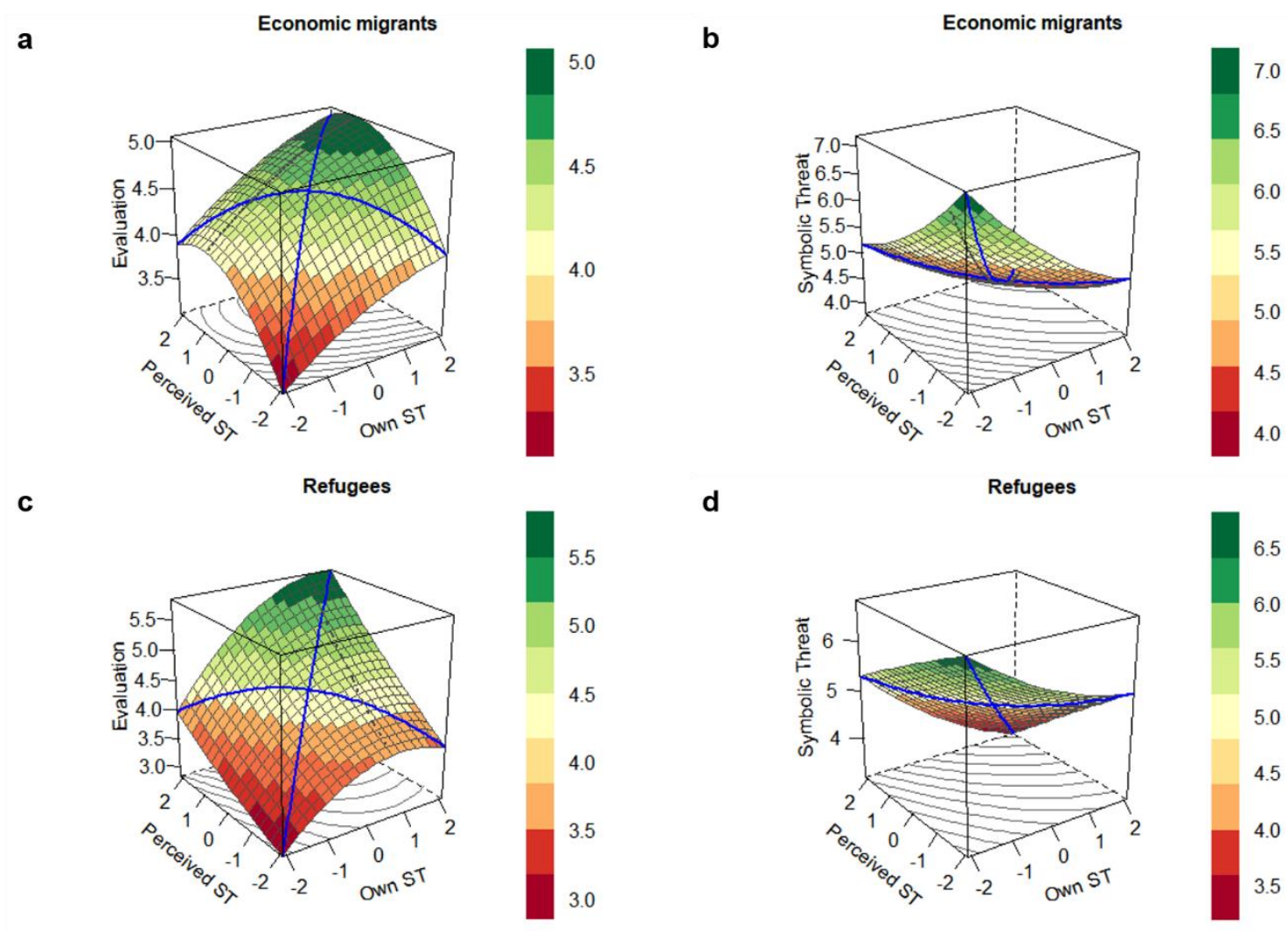

Figure 9. Study 2: Response surface analyses plots illustrating consistent linear effects of own and perceived self-transcendence versus self-enhancement (“ST") on evaluation and symbolic threat, for both refugees and economic migrants as the target groups.

Higher own and perceived values predicted more favorability on both outcomes and for both target groups. There were no indications of dissimilarity effects.

On the conservation versus openness dimension, the effect of participants' own values was non-significant, $t(101.34)=-1.88, p=.063$, but pointed in the expected direction. The univariate effects for evaluation, $b=-0.10, S E=0.06, \beta=-0.12, p=.12$, and symbolic threat, $b=0.18, S E=0.10, \beta=0.16, p=.070$, were both non-significant. Perceived values on this dimension did not relate to evaluation and symbolic threat from the target groups, $t(407.97)=-1.56, p=.12$.

The interaction term, $t(397.66)=0.52, p=.61$, the quadratic term of participants' own conservation versus openness values $t(102.95)=-0.73, p=.47$, and the quadratic term of perceived conservation versus openness values were non-significant, $t(99.74)=3.02, p=.051$. 
However, as mentioned above, the interaction term between own and perceived conservation versus openness values showed differential effects between the target groups. For economic migrants, the interaction term was non-significant across both outcomes, $t(98)=-0.36, p=.72$. For refugees, the interaction term was also non-significant after correcting for the dual comparison, $t(98)=2.05, p=.043$, but it pointed in the expected direction. Similarly, although both univariate regressions showed non-significant interaction terms on both evaluation, $b=0.14, S E=0.08, \beta=0.16, p=.093$, and symbolic threat, $b=-0.25, S E=0.13, \beta=-0.20, p=.055$, both effects pointed in the expected direction.

As in Study 1, we explored this effect further by computing an average across evaluation and symbolic threat and conducting a simple slopes analysis. This analysis showed that when refugees were perceived to be lower in conservation values $(-1 S D)$, participants higher in conservation values evaluated refugees less favorably, $b=-0.24$, $S E=0.10, t(95)=-2.31, p=.023,95 \%$ CI $[-0.45,-0.03]$. Put differently, when refugees were perceived to be higher in openness values, participants higher in openness values evaluated them more favorably. In contrast, at higher perceived conservation values $(+1 S D)$, there was no effect of own values on the outcomes, $b=0.01, S E=0.09, t(95)=0.16, p=.87,95 \%$ CI $[-0.16$, 0.18]. As illustrated in the RSA plots $\mathrm{c}$ and $\mathrm{d}$ in Figure 10, these findings indicate a nonsignificant tendency for a dissimilarity effect when refugees were viewed as higher in openness values. Here, higher own openness values were linked with more favorability toward refugees and higher own conservation values with less favorability. There was also a non-significant trend for higher conservation values to predict lower favorability, which is mainly apparent for economic migrants, as depicted in plots a and b. See Tables 1 and 2 for all univariate tests. 


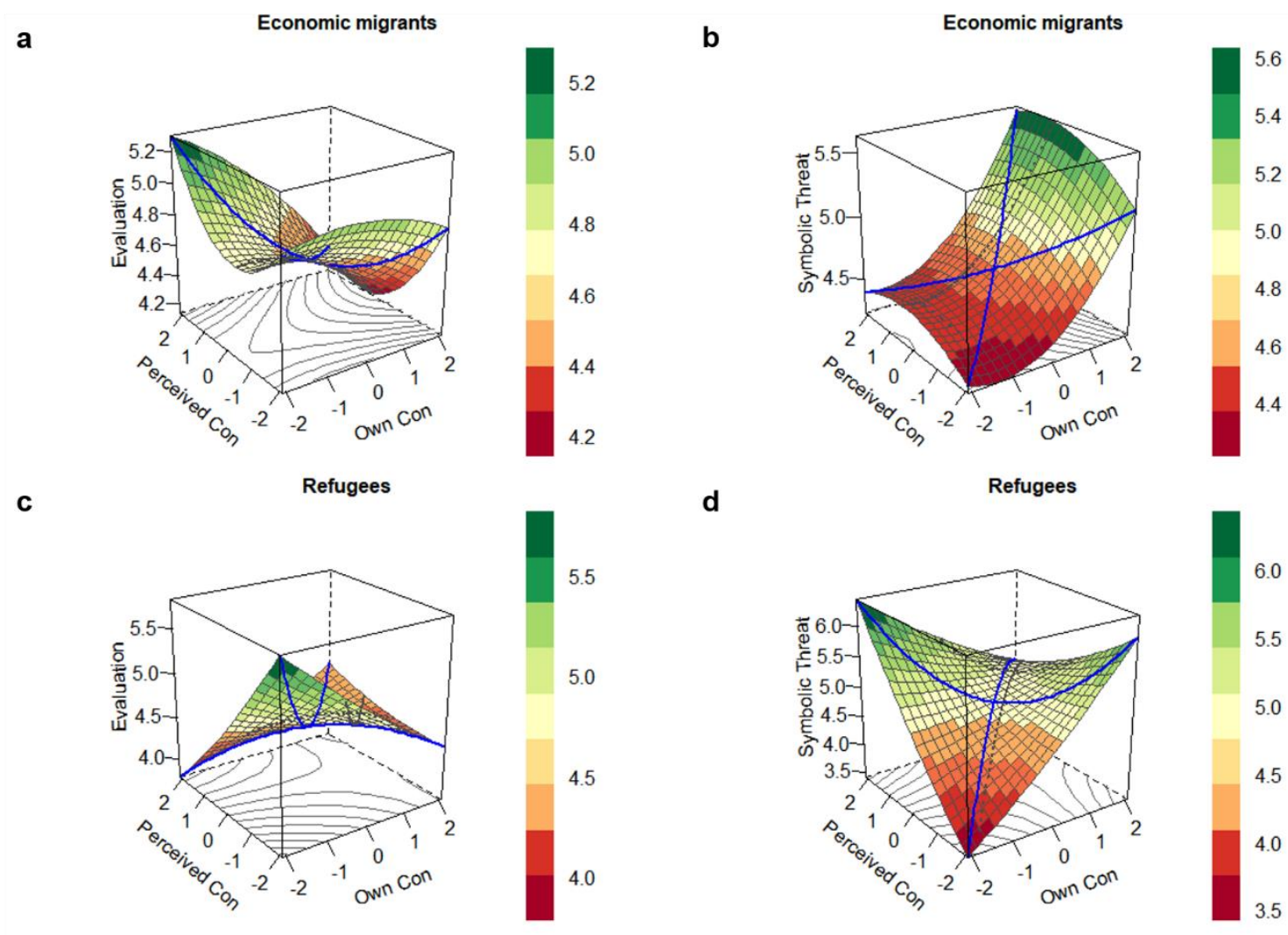

Figure 10. Study 2: Response surface analyses plots illustrating effects on the conservation versus openness values dimension ("Con") on evaluation and symbolic threat, for both refugees and economic migrants as the target groups. There was a nonsignificant tendency for higher own conservation values to predict lower favorability across outcomes and target groups. There were non-significant indications for dissimilarity effects for refugees but not economic migrants: favorability toward refugees tended to be lower when individuals who held higher conservations values perceived refugees to value openness more (i.e., at -2 "own Con" and +2 "perceived Con").

Mediation by motivation to be non-prejudiced. We first tested whether the mediation pattern differed between the two target groups refugees and economic migrants. As can be seen in Figure 11, we used the same mediation model as in Study 1 for both refugees and economic migrants. In a constrained model, we set equality constraints for each regression term between target groups and compared it to a free model where all regression weights were 
estimated as free parameters. The constrained model showed better model fit, $\chi^{2}(28)=66.25$, $\mathrm{AIC}=1316.12, \mathrm{BIC}=1361.24$, than the free model, $\chi^{2}(23)=62.68, \mathrm{AIC}=1322.55, \mathrm{BIC}=1380.94$, and we therefore collapsed across target groups in the mediation analyses. Figure 11 shows that MNPS mediated the effects of own self-transcendence versus self-enhancement values, but not of own conservation versus openness values on the latent favorability toward the immigrant groups.

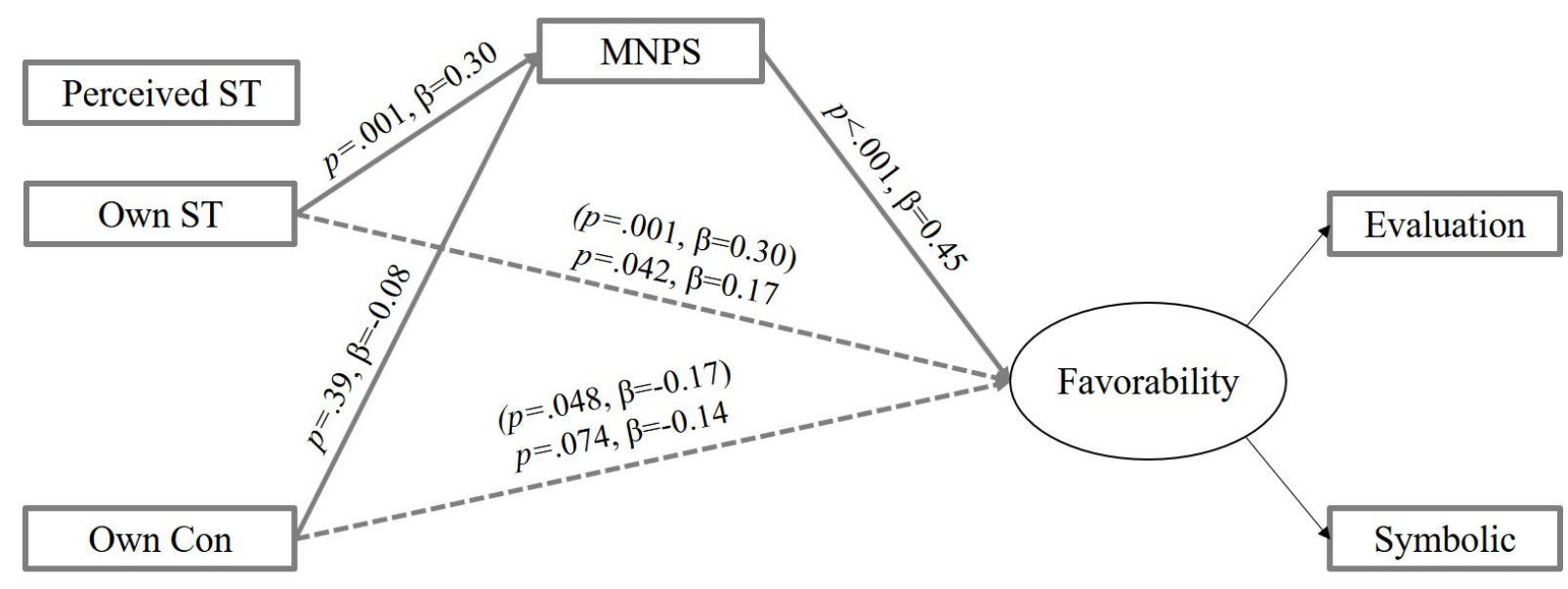

Perceived Con

$\underline{\text { Indirect effect }}$

ST: $b=0.11, S E=0.04$, CI 95\% $[0.03,0.19]$

CO: $b=-0.02, S E=0.03$, CI 95\% [-0.07, 0.03]

Figure 11. Study 2: Motivation to be non-prejudiced (MNPS) mediated the effects of own self-transcendence versus self-enhancement values ("ST") on evaluation and perceived symbolic threat. In contrast, MNPS did not mediate an effect of own conservation versus openness values ("Con") on the outcomes. Both pathways controlled for the influence of perceived values.

\section{Discussion}

Study 2 found that individuals higher in self-transcendence values and those who perceived refugees and economic migrants to be higher in self-transcendence values expressed lower prejudice against these groups, supporting our hypotheses concerning this dimension (H1A \& H2A). In addition, as expected, the effects of own self-transcendence 
versus self-enhancement values were again mediated by self-regulated motivation to be nonprejudiced (H3A). In contrast, the polynomial regression analyses showed an absence of dissimilarity effects on this dimension as in Study 1 (H4A). Together, these results replicate our findings of Study 1, and they are consistent across outcome measures and immigrant groups.

On the conservation versus openness dimension, individuals' own conservation values showed a non-significant tendency to predict higher prejudice, and this tendency was not mediated by the motivation to be non-prejudiced, contrary to our expectations (H1B \& H3B). Perceptions of conservation versus openness values were not linked with the outcomes. Interestingly, Study 2 showed a non-significant tendency that replicated the dissimilarity effects on the conservation versus openness values dimension found in Study 1 (H4B). However, this tendency was only found for refugees as the target group and not economic migrants. Specifically, this tendency suggested that when refugees were seen to be higher in openness values, individuals higher in conservation values were less favorable toward the group.

Hence, although the value dissimilarity effect in Study 2 was weaker than in Study 1 and was only obtained for refugees and not economic migrants, it is important to note that the effect consistently emerged for dissimilarities with immigrant openness values and that it showed a similar shape as in Study 1 for Muslim immigrants. Accordingly, the findings across both studies support the notion that values along this dimension, and openness values in particular, are more relevant to dissimilarity effects on prejudice. Moreover, this effect may only emerge for some groups but not others. In contrast, value dissimilarity effects on the self-transcendence versus self-enhancement dimension were consistently absent. One caveat to contextualize these findings is that Study 2 used a within-subjects design to present the target groups. This particular approach, namely presenting participants with both target groups successively, may have increased the salience of intergroup differences between 
refugees and economic migrants, leading participants to spontaneously compare the groups to each other rather than comparing each group to themselves. To address this concern, the following study replicated and expanded Study 2 by using a between-subjects design. This enabled a test of conceptual replication across a different experimental paradigm.

\section{Study 3}

To conceptually replicate and expand on the previous study, Study 3 presented the same targets as Study 2 - refugees and economic migrants - but now in a between-subjects design. In addition, Study 3 also assessed participants' perceptions of their ingroup's values. By adding this measure, we explored whether intergroup value dissimilarities reveal a similar pattern of results as self-immigrant value dissimilarities.

Intergroup dissimilarity is likely to invoke different perceptions and feelings about the outgroup than self-outgroup dissimilarity. From a personal perspective, dissimilar values may be seen as threatening our personal way of life. For instance, someone who values selfdiscipline or preserving traditions (conservation values) may feel personally threatened by immigrants perceived as valuing independence and an exciting life (openness values). In contrast, from an ingroup's perspective, an outgroup perceived as possessing highly dissimilar values may raise concerns about integration and assimilation, and about intergroup harmony and conflict (Rohmann, Florack, \& Piontkowski, 2006).

Despite these expectable differences between an individual and group-level perspective, theories and research on intergroup value dissimilarity generally predicted and found that higher intergroup value dissimilarity links to higher prejudice (e.g., Schwartz et al., 1990; Struch \& Schwartz, 1989), mirroring predictions and findings for self-immigrant value dissimilarity (e.g., Dunbar et al., 2000; Haddock et al., 1993). Moreover, past research on intergroup value dissimilarity reveals similar issues as research on self-outgroup value dissimilarity: They used problematic profile correlations which may have overstated or misrepresented the findings, examined value dissimilarity as a global index across value 
dimensions, and did not consider the influence of perceived ingroup and outgroup values.

Hence, similar to our main aim in this research, Study 3 used polynomial regression analyses and a novel focus on separate value dimensions to examine the link between intergroup value dissimilarity and prejudice in more detail. We expected weaker effects for these evaluations on a group level, in line with previous suggestions that individuals react more strongly to individual-level threats (Gaertner et al., 2002; Leonardelli et al., 2010).

\section{Method}

Participants. As in the previous two studies, we aimed for a power of .80 to detect a medium effect size, and a target of 164 participants, or 82 participants in each betweensubject condition. As before, we recruited additional participants to meet these sample size requirements after participant exclusion. Thus, 186 participants took part in an online study at [anonymized for review]. Consistent with our previous exclusion criteria, we restricted all reported analyses to 161 non-Muslim British participants (144 women, 15 men, 2 preferred not to answer; $18-47$ years of age, $M_{\mathrm{age}}=19.71$ ). The sample size unexpectedly fell short of the required sample size in both conditions, with 80 participants in the economic migrants condition and 81 participants in the refugees condition. Nonetheless, the achieved power was between .79 and $.80 .^{11}$

Of the remaining participants, 146 entered the UK as their birthplace. One hundred and fifty-one participants identified as White European, four as Asian, and six indicated 'Other' as their ethnicity. One hundred and nine participants were non-religious, 43 were of Christian faith, two of Hindu faith, and seven indicated 'Other' as their religion. Participants completed the survey in February 2016 in approximately 15 minutes and were compensated in course credit.

Procedure and instruments. Participants received either a description of immigrants as economic migrants or as refugees. These descriptions were the same as in Study 2. Next, we administered the SSVS to measure perceived values of the immigrant group, and we 
measured participants' evaluations and perceptions of symbolic threat from the presented immigrant group with the same items as in Study 2. The Tucker's congruence coefficients indicated a good fit for both value measures (economic migrants: .999; refugees: .986). The reliabilities of the evaluation items (refugees: $\alpha=.87$; economic migrants: $\alpha=.91$ ) and the symbolic threat items (refugees: $\alpha=.85$; economic migrants: $\alpha=.81$ ) were good.

Subsequently, participants completed the MNPS. The only difference from Study 2 was that participants indicated the reasons for trying to be unprejudiced toward the respective immigrant group, (economic migrants or refugees). The internal reliability of the MNPS was good $(\alpha \mathrm{s}>.80) .{ }^{12}$ We then measured participants' own values and their perception of British values with the SSVS. The Tucker's congruence coefficients indicated a good fit for both value measures (own: .997; British: .994). ${ }^{8,13}$

\section{Results}

Preliminary analyses. As in Study 2, we first tested whether the effects of values on favorability showed different patterns for the target groups, refugees and economic migrants. In a constrained model, we set equality constraints for each regression term between target groups and compared this to a free model, where all regression weights were estimated as free parameters.

The constrained model showed better model fit, $\chi^{2}(28)=19.88, \mathrm{AIC}=846.53$, $\mathrm{BIC}=914.32$, than the free model, $\chi^{2}(18)=90.95, \mathrm{AIC}=846.66, \mathrm{BIC}=945.26$. To confirm this finding in regression analyses, we tested for all possible interactions of each regression term with target group. None of these interactions reached significance. Hence, given that the pattern of effects does not differ between the target groups, we collapsed across target groups in the main analyses. We nevertheless produced RSA plots for each target group (and each outcome) separately to be able to compare plots across studies. All univariate regression outcomes can be found in Table 1 and 2. 
Main analysis. We analyzed the data using the ' $1 \mathrm{~m}$ ' function in R. The outcomes evaluation and symbolic threat were regressed onto participants' own and perceived values in the first step, their interaction terms in the second step, and their quadratic terms in the third step. We also controlled for target group by including it as a predictor in the first step. The multivariate tests showed a significant effect of participants' values on the self-transcendence versus self-enhancement dimension, $F(2,154)=8.50, p<.001$, which indicated that participants higher in self-transcendence values evaluated the target groups more favorably on both outcomes, $b=0.32, S E=0.09, \beta=0.29, p<.001$ (evaluation), $b=-0.47, S E=0.12, \beta=-0.29, p<.001$ (symbolic threat). The effect of perceived values on this dimension was non-significant, $F(2,154)=2.62, p=.076$, but pointed in the expected direction. Similarly, the univariate tests were non-significant after correcting for the dual comparison but pointed in the expected direction: perceiving the immigrant groups as higher in self-transcendence values predicted more positive evaluations, $b=0.18, S E=0.08, \beta=0.19, p=.030$, and lower symbolic threat, $b=-0.23, S E=0.11, \beta=-0.18, p=.042$. The interaction term, $F(2,152)=0.05, p=.95$, and the quadratic terms for participants' values, $F(2,148)=0.79, p=.46$, and their perceived values, $F(2,148)=1.36, p=.26$, were non-significant. As illustrated in Figure 12, these findings indicate an effect for participants' self-transcendence versus self-enhancement values, a nonsignificant tendency for perceived values, and an absence of a dissimilarity effect on prejudice. 


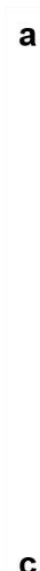

C
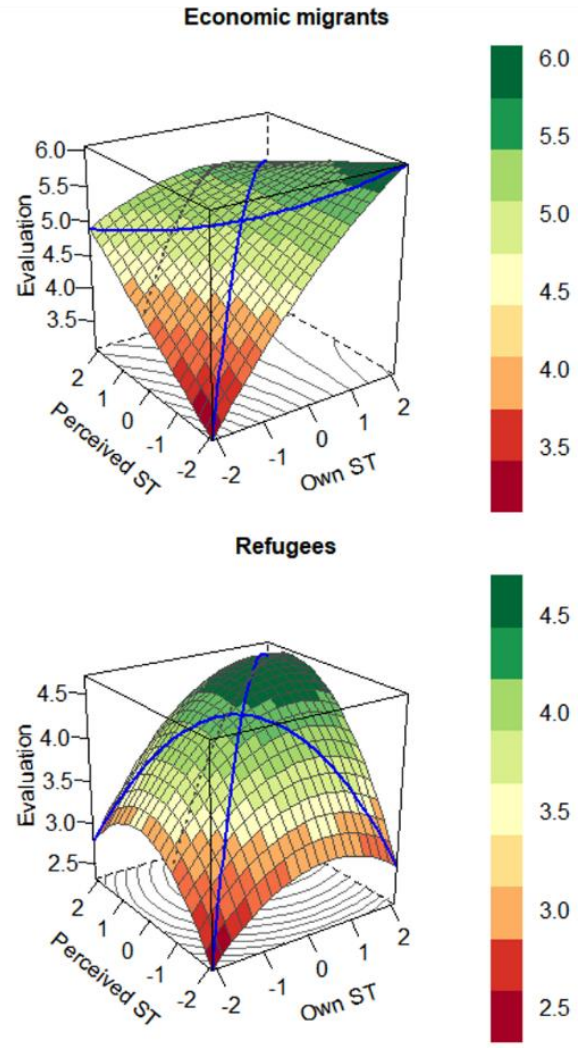

b

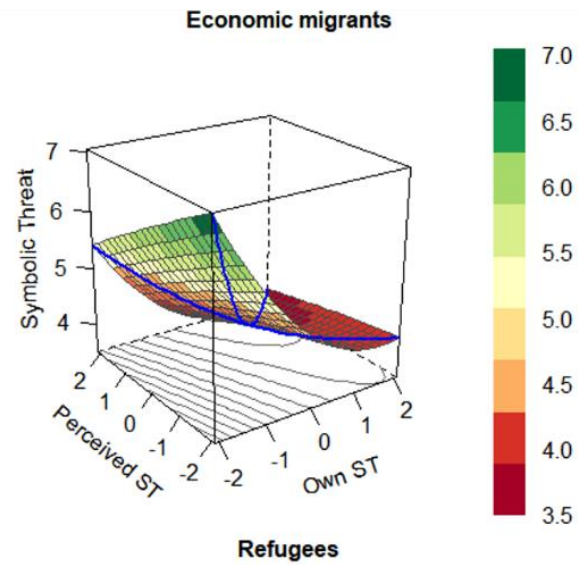

d

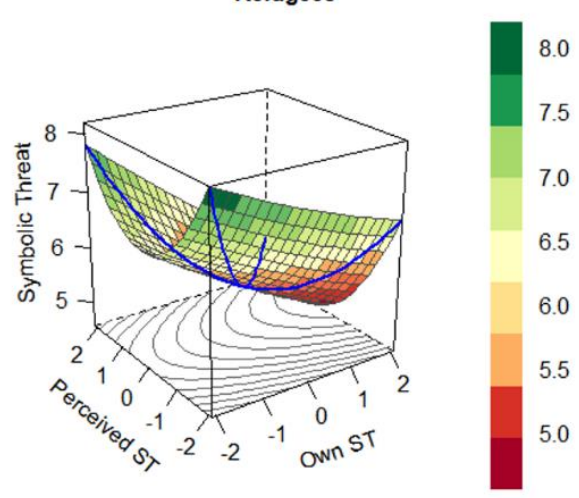

Figure 12. Study 3: Response surface analyses plots illustrating that own selftranscendence versus self-enhancement ("ST") predicted higher evaluation and lower symbolic threat for both refugees and economic migrants as the target groups. There were no indications of dissimilarity effects on this values dimension.

On the conservation versus openness dimension, the multivariate test for participants' own values was significant, $F(2,154)=5.66, p=.004$, indicating that participants' higher in conservation values evaluated the target groups more negatively on evaluation, $b=-0.16$, $S E=0.06, \beta=-0.21, p=.005$, and symbolic threat, $b=0.27, S E=0.08, \beta=0.24, p=.001$. The multivariate test for perceived values was non-significant, $F(2,154)=0.22, p=.80$. The quadratic terms of own and perceived conservation versus openness values were nonsignificant, $F(2,148)=0.70, p=.50, F(2,148)=0.18, p=.83$, respectively.

The interaction term on this values dimension was significant, $F(2,152)=3.19, p=.044$. The univariate tests showed a significant interaction on evaluation, $b=0.14, S E=0.06, \beta=0.29$, $p=.015$, and an interaction term for symbolic threat that was non-significant after multiple 
comparison correction, but which pointed in the expected direction, $b=-0.18, S E=0.08$, $\beta=-0.25, p=.032$. To break this interaction down, we computed an average across evaluation and symbolic threat and conducted a simple slopes analysis. When the target groups were perceived to be higher in openness values $(-1 S D)$, participants higher in conservation values evaluated them less favorably, $b=-0.32, S E=0.08,95 \%$ CI $[-0.48,-0.15]$. Put differently, when the immigrant groups were perceived to be higher in openness values, participants higher in openness values evaluated them more favorably. In contrast, at higher perceived conservation values $(+1 S D)$, there was no effect of own values on evaluations, $b=-0.08$, $S E=0.07,95 \%$ CI $[-0.22,0.06]$.

Figure 13 illustrates a dissimilarity effect when the target groups were perceived to be higher in openness values. As can be seen in the figure, the surface is somewhat askew due to the influence of the linear effect of own conservation versus openness values, but otherwise comparable to the RSA plots in Figures 6 and 10c/d. 
a

C
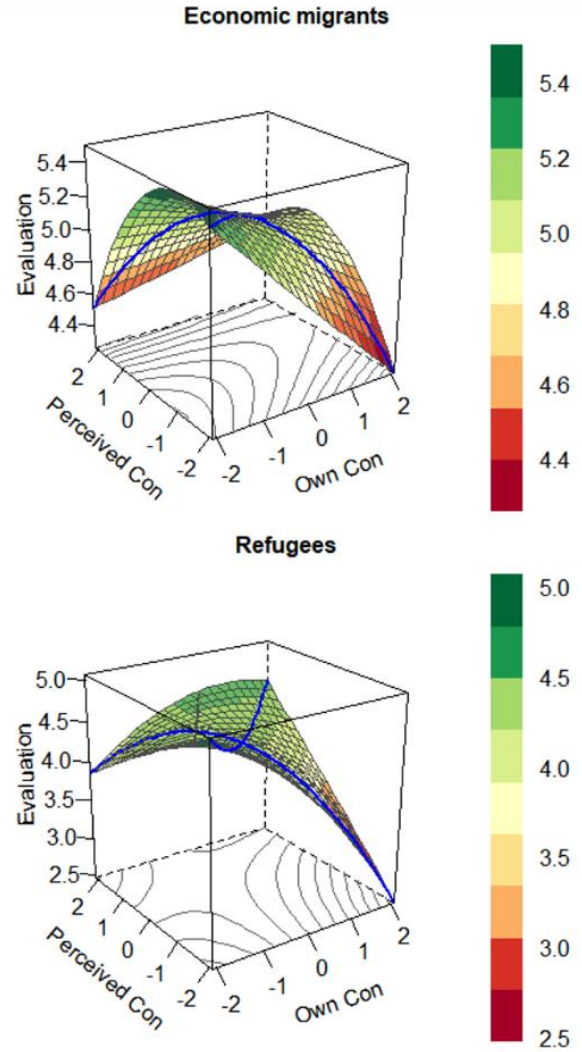

b

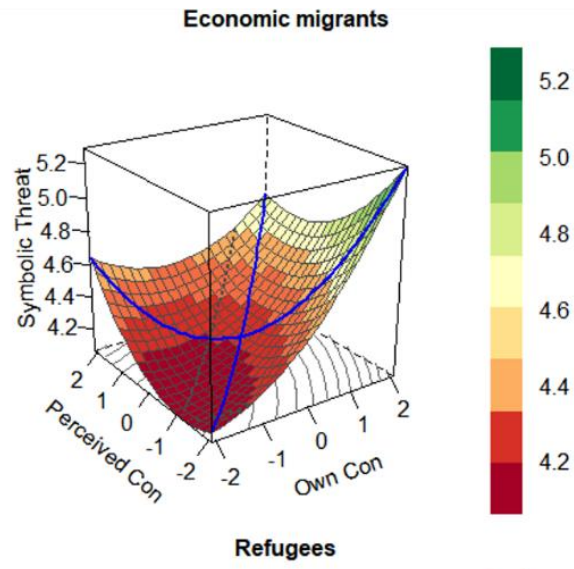

d

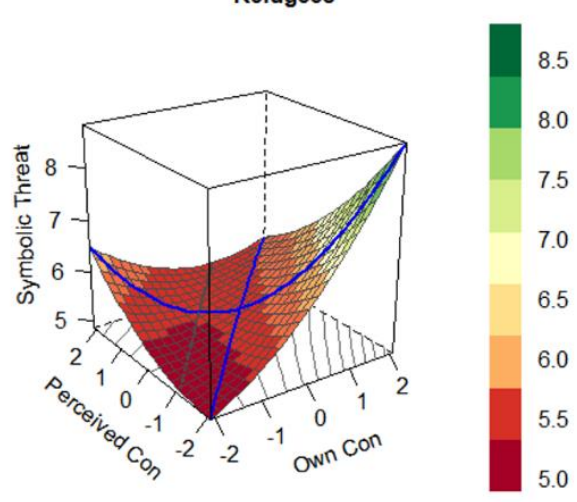

Figure 13. Study 3: Response surface analyses plots illustrating effects on the conservation versus openness values dimension ("Con") on evaluation and symbolic threat, for both refugees and economic migrants as the target groups. Higher own conservation values to predicted lower favorability across outcomes and target groups. The data indicated a dissimilarity effect: Favorability toward both groups was lower when individuals who held higher conservation values perceived the groups to value openness more (i.e., at -2 "own Con" and +2 "perceived Con").

Mediation by motivation to be non-prejudiced. As in Study 2, we first tested whether the mediation pattern differed between the two target groups refugees and economic migrants. We used the same models as in Study 2 to compare a constrained model with equality constraints between target groups with a model where regression weights were estimated freely. The constrained model showed better model fit, $\chi^{2}(14)=9.52, \mathrm{AIC}=1299.22$, $\mathrm{BIC}=1385.50$, than the free model, $\chi^{2}(8)=2.95, \mathrm{AIC}=1304.65, \mathrm{BIC}=1409.41$, and we therefore collapsed across target groups in the mediation analyses. Figure 14 shows that MNPS 
mediated the effects of own self-transcendence versus self-enhancement and conservation versus openness values on the latent factor favorability toward both target groups. See Tables 5 and 6 for the descriptive statistics and correlations among all study variables.

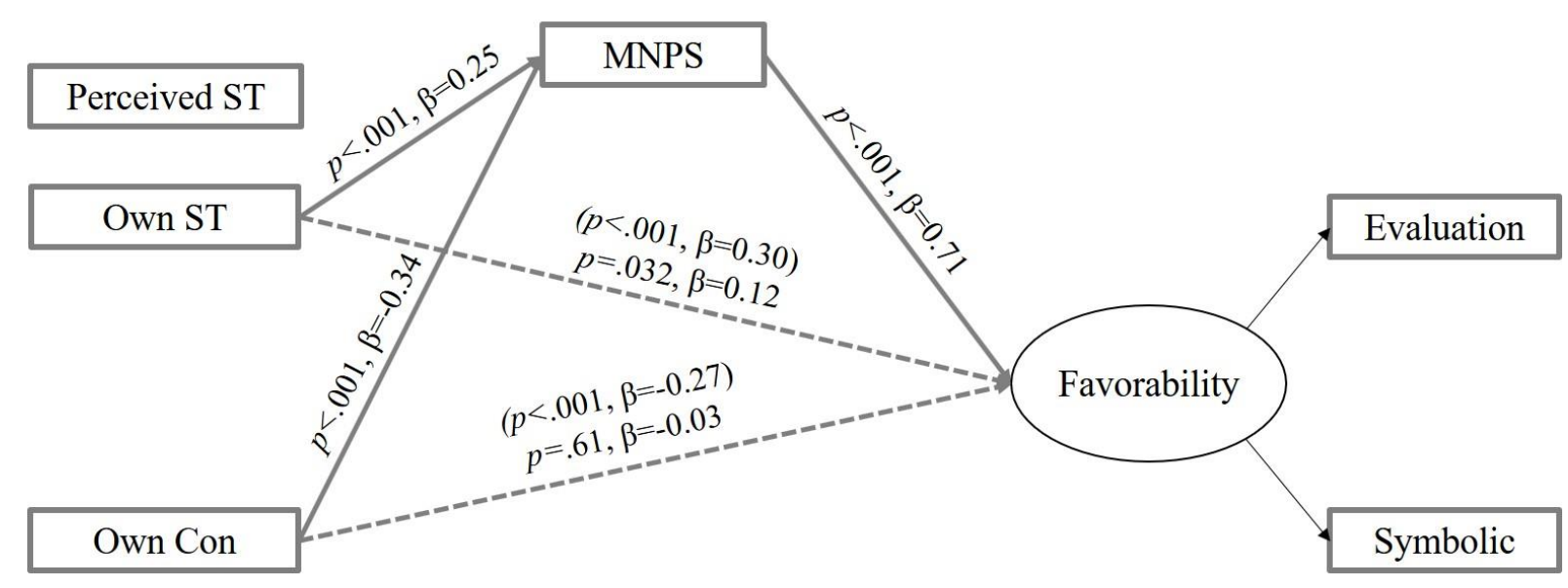

Perceived Con

$\underline{\text { Indirect effect }}$

$$
\begin{aligned}
\text { ST: } b=0.19, S E & =0.05, \text { CI 95\% }[0.09,0.29] \\
\text { CO: } b=-0.16, S E & =0.04, \text { CI 95\% }[-0.23,-0.09]
\end{aligned}
$$

Figure 14. Study 3: Motivation to be non-prejudiced (MNPS) mediated the effects of own self-transcendence versus self-enhancement values ("ST"), and of own conservation versus openness values ("Con") on evaluation and perceived symbolic threat. Both pathways controlled for the influence of perceived values.

Intergroup value dissimilarity. Study 3 also examined whether value dissimilarity between the perceived values of British people and the perceived values of the immigrant groups predicted the outcomes. The outcomes evaluation and symbolic threat were regressed onto perceived British values and perceived immigrant values in the first step, their interaction terms in the second step, and their quadratic terms in the third step. We also controlled for target group by including it as a predictor in the first step.

On the self-transcendence versus self-enhancement value dimension, the effect of perceived British values was non-significant, $F(2,154)=0.73, p=.48$. In contrast to the main analysis, perceived immigrant values on this dimension showed a significant effect, 
$F(2,154)=6.71, p=.002$. In particular, higher perceived self-transcendence values in immigrants predicted more positive evaluations, $b=0.23, S E=0.08, \beta=0.26, p=.002$, and lower symbolic threat, $b=-0.30, S E=0.11, \beta=-0.23, p=.006$. The interaction term, $F(2,152)=0.77$, $p=.47$, the quadratic term of perceived British values, $F(2,148)=0.77, p=.47$, and the quadratic term of perceived immigrant values, $F(2,148)=1.06, p=.35$, were non-significant.

On the conservation versus openness value dimension, the effects of perceived British values, $F(2,154)=0.02, p=.99$, and of perceived immigrant values, $F(2,154)=0.12, p=.89$, were non-significant. The interaction, $F(2,152)=0.34, p=.71$, the quadratic term of perceived British values, $F(2,148)=0.97, p=.38$, and the quadratic term of perceived immigrant values, $F(2,154)=0.09, p=.91$, were non-significant.

\section{Discussion}

Study 3 found that individuals higher in self-transcendence values expressed lower prejudice toward refugees and economic migrants, consistent with our hypotheses (H1A) and consistent with the findings in Study 1 and 2. Although the effects for perceived selftranscendence versus self-enhancement values did not reach conventional levels of significance, they trended in the expected direction and were in line with the consistent effects in Study 1 and $2(\mathrm{H} 2 \mathrm{~A})$. These trends suggested that perceiving refugees and economic migrants to more highly value self-transcendence tended to predict lower prejudice. In addition, the effects of own self-transcendence versus self-enhancement values on favorability toward the target groups were mediated by the motivation to be non-prejudiced, as expected (H3A) and in line with Study 1 and 2. Finally, a value dissimilarity effect was again absent on this value dimension, as in Studies 1 and 2 (H4A).

On the conservation versus openness dimension, individuals higher in conservation values were less favorable toward the immigrant groups, and this link was mediated by the motivation to be non-prejudiced, supporting our hypotheses (H1B \& H3B). As before, perceptions of immigrants' conservation versus openness values were not related to the 
outcome measures. Interestingly, Study 3 replicated the dissimilarity effects on this value dimension across both target groups. Specifically, this effect showed that when the immigrant groups were seen to be higher in openness values, individuals higher in conservation values were less favorable toward the groups. Our General Discussion considers the success of Study 3's between-subjects design in revealing this effect, as compared to the within-subjects design in Study 2.

Finally, Study 3 also explored whether intergroup value dissimilarity related to the prejudice outcomes. All effects of intergroup value dissimilarity, and of perceived ingroup values, were non-significant, in line with previous suggestions that group-level threats elicit weaker reactions than individual-level threats (Gaertner et al., 2002; Leonardelli et al., 2010). That is, using polynomial regression analyses revealed a general absence of intergroup value dissimilarity effects on prejudice, contrary to previous research (Schwartz et al., 1990; Struch \& Schwartz, 1989).

\section{General Discussion}

The present research found that values are related to prejudice in a multi-faceted manner. Three studies showed consistently that prejudice toward Muslim immigrants, refugees, and economic migrants was lower among individuals who attach more importance to self-transcendence values (e.g., equality) than to self-enhancement values (e.g., power). We also found that this link was accounted for by the more concrete motivation to be nonprejudiced. That is, individuals higher in self-transcendence values had a more internalized, or self-regulated motivation to be non-prejudiced, and this internalized motivation in turn explained their lower prejudice against immigrants. Moreover, we found that prejudice tended to be lower when immigrant groups were perceived to value self-transcendence principles more than self-enhancement values. These findings were in line with previous evidence as we will discuss below. 
The link between own conservation versus openness values was inconsistent across studies. That is, only Study 3 found that individuals' conservation values predicted higher prejudice, whereas this association was absent in Studies 1 and 2. Moreover, Studies 1 and 3, but not Study 2, found that this link was mediated by the motivation to be non-prejudiced. In addition to these mixed findings for own values, perceptions of immigrants' values on this dimension were consistently unrelated to the outcomes.

Interestingly, however, the present research provides the first evidence of value dissimilarity effects on this dimension. In particular, when the immigrant groups were perceived to value openness more (e.g., independence, an exciting and varied life), individuals higher in conservation values (e.g., tradition, security, self-discipline) generally expressed higher prejudice toward them. Put differently, individuals higher in openness values evaluated immigrant groups more favorably when they perceived them to place more value on openness. While Study 2 only found a non-significant tendency of this effect for refugees and no effect for economic migrants, it is noteworthy that the within-subject design of Study 2 may have made comparisons between groups more salient than comparisons between each group and oneself. We speculated that this particular design may have reduced the strength of any self-immigrant value similarity effects. Supporting this speculation, Study 3 found when participants only viewed one immigrant group, self-immigrant groups emerged consistently across both target groups. It is also important to note that this self-immigrant value dissimilarity effect revealed a consistent shape across all three studies, across all three target groups, and across both outcome measures. Hence, we can conclude that perceived dissimilarities with immigrant openness values generally related to higher prejudice. In contrast, perceived dissimilarities with immigrant conservation values, self-transcendence values, and self-enhancement values were consistently unrelated to favorability toward immigrants. Figure 15 depicts the relationships that received largely consistent support in the present research. 


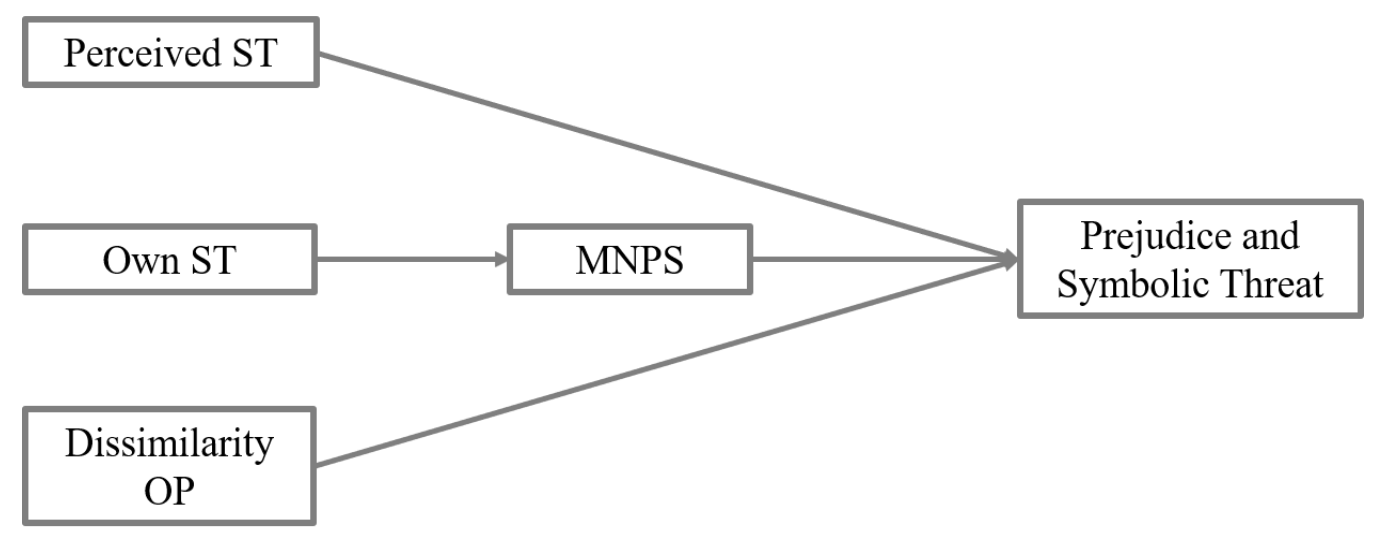

Figure 15. Model supported by the present research, across the target groups Muslim immigrants, refugees, and economic migrants. ST=self-transcendence versus selfenhancement values. $\mathrm{OP}=$ openness values. $\mathrm{MNPS}=$ motivation to be non-prejudiced.

\section{Individuals' Own Values}

The finding that higher self-transcendence values predict lower prejudice against immigrants is consistent with earlier work (Bernard et al., 2003; Davidov et al., 2008; Leong \& Ward, 2006; Saroglou et al., 2009; Vecchione et al., 2012). Interestingly, this finding emerged consistently across the range of different immigrant groups, despite differences in how the groups were perceived (e.g., refugees were rated to be more deserving of help and higher in self-transcendence values than economic migrants; see supplementary analyses). Hence, this finding attests to the robust nature of the link between own self-transcendence versus self-enhancement values and prejudice.

Further, the present research showed that this link was accounted for by the motivation to be non-prejudiced. This finding reveals an important interconnection between research on values, motivation, and prejudice - three constructs often examined only in pairs rather than together. In theory, values exert their effects by guiding goals in particular situations (Feather, Norman, \& Worsley, 1998; Maio, 2016; Schwartz, 1992), but evidence for this process is relatively sparse. The present findings suggest that values can activate motives to 
be non-prejudiced for specific groups, which is more proximal to specific attitudes and behavior.

For individuals' conservation versus openness values, the present studies generally revealed mixed effects on prejudice against immigrants, whereas previous research linked higher own conservation values to more negativity toward immigrants (Davidov et al., 2008; Leong \& Ward, 2006; Schwartz, 2007; Schwartz et al., 2010; Vecchione et al., 2012). It is noteworthy that these mixed findings were not due to our polynomial regression methodology - correlations revealed similarly mixed results for this dimension. It is possible that effects of conservation values were suppressed in our predominantly young sample, whereas previous studies either recruited older samples (e.g., Schwartz et al., 2010) or a wider range of ages in cross-national surveys (e.g., Davidov et al., 2008). This speculation is in line with previous findings that young people have lower conservation values and show lower prejudice (e.g., Egri \& Ralston, 2004; Gonsalkorale, Sherman, \& Klauer, 2009; Nosek, Banaji, \& Greenwald, 2002). Future research could address this limitation by examining whether the findings generalize to older participants and different socio-economic groups. In the interim, our findings show that the previously inferred links with conservation values should no longer be taken as a given fact, especially for younger people, and our findings further underscore our argument that the role of values in prejudice depends on which values dimensions are examined.

\section{Perceptions of Immigrant Values}

The present research found that higher perceived self-transcendence values of immigrants generally predict higher favorability, whereas perceived values on the conservation versus openness value dimension were unrelated to prejudice-related outcomes. This pattern is largely in line with previous evidence examining perceptions of values in German-Israeli evaluations (Schwartz et al., 1990), wherein perceptions of self-transcendence values were linked with more positive social motives toward the outgroup. Our findings 
extend this previous evidence by demonstrating that perceived self-transcendence versus selfenhancement values of immigrants relate to prejudice even independently of individuals' own values, that is, when individuals' own values are controlled for. Moreover, the present research extends previous scarce evidence by testing a range of novel groups of widespread contemporary relevance.

\section{Value Dissimilarities}

Previous examinations of the links between value dissimilarity and prejudice have generally found a uniform relationship with higher value dissimilarity predicting higher prejudice (e.g., Dunbar et al., 2000; Schwartz et al., 1990). However, as discussed in the Introduction, this research has used (absolute) difference scores or profile correlations which are likely to have overstated and misrepresented this link (Edwards, 1993, 1994, 2002; Griffin et al., 1999). In addition, previous research has ignored the possibility that value dissimilarity effects may differ depending on which value dimension is considered (e.g., Abbott et al., 2005). Redressing these shortcomings, the present research used polynomial regression analyses and response surface analyses plots to examine value dissimilarity effects on prejudice in a statistically valid, detailed, and illustrative manner (Barranti et al., 2017; Edwards, 2002; Humberg et al., 2018).

Using this analytical approach, the present research revealed a new level of nuance about value dissimilarity effects. Specifically, we found that value dissimilarities emerge specifically in comparisons between one's own conservation values and an outgroup's perceived openness values. While Study 2 showed a weaker pattern of this effect, and only obtained this tendency for refugees and not economic migrants, it is noteworthy that this study may have made comparisons between groups more salient than comparisons of the groups with oneself. In line with this speculation, Study 3 presented each target group separately and found value dissimilarity effects across both refugees and economic migrants. Moreover, the particular shape of this dissimilarity effect was highly similar in all three studies, for all three 
target groups, and on both outcomes. It is noteworthy that this dissimilarity effect generally emerged in the absence of linear and quadratic effects. This additional finding suggests that the response surface of expected values was not askew or shifted, or in other words, higher favorability was indeed found at the extreme points of similarity between own and perceived values (e.g., scores of +2 on both) and lower favorability was indeed found at the points of dissimilarity (i.e., scores of +2 on own values and -2 on perceived values). Moreover, the absence of quadratic effects suggests that similarity effects were stronger at extreme values of own and perceived values and weaker at midrange values. In addition, all three studies showed a consistent absence of dissimilarity effects on the self-transcendence versus selfenhancement dimension.

Importantly, although these findings partially contradict the previously identified uniform relationship between value dissimilarity and prejudice, they are consistent with seminal theories in the prejudice literature which suggest a more complex and nuanced pattern. In particular, while self-categorization theory (Turner et al., 1987), belief congruence theory (Rokeach et al., 1960), and similarity-attraction theory (Byrne, 1961; Byrne \& Wong, 1962) predict that higher dissimilarity generally links with higher prejudice, social identity theory (Tajfel \& Turner, 1979) and optimal distinctiveness theory (Brewer, 1991) indicate that being too similar to others or other groups can threaten one's or the ingroup's sense of uniqueness. These conflicting perspectives have been highlighted in previous research (e.g., Jetten et al., 2004), which has found that value dissimilarity effects can emerge that are in line with either of the predictions, depending on the circumstances (i.e., identification, outcome measure). Accordingly, the conflicting predictions may also apply to differing degrees to the present research. Specifically, while higher value dissimilarity may indeed generally predict higher prejudice, this pattern could have been masked because individuals felt that their uniqueness was threatened at higher levels of value similarity. This may explain the absence 
of dissimilarity effects when immigrants were perceived to be higher in conservation values, self-transcendence values, and self-enhancement values.

In contrast, individuals higher in openness values still show a value dissimilarity effect, perhaps because for them, high value similarity with immigrants is experienced as less threatening. This explanation is based on findings that individuals who value openness are less identified with their ingroup (Roccas et al., 2010), and those less identified have been shown to experience lower similarity threat and to reveal a general dissimilarity effect on prejudice (Jetten et al., 2004). Hence, the present findings suggest that previous assertions that higher value dissimilarity generally predicts more prejudice (e.g., Dunbar et al., 2000; Rokeach et al., 1960) only apply when high similarity is not perceived as threatening, as appears to be the case among those higher in openness values. It would be fruitful to examine these explanations for differential value dissimilarity effects more closely in future research.

The obtained dissimilarity effects are also consistent with the nature of the particular values. That is, among individuals who attach higher importance to such conservation values as social order, tradition, and security, viewing immigrants as having opposing values such as independence, freedom, and a varied life conceivably represents a threat to their worldview and way of life. In contrast, individuals who attach more importance to such values as curiosity, freedom, and a varied life may see immigrants as individuals with an interesting background and a different perspective on life. Hence, these individuals may view immigrants as likely to satisfy their thirst for curiosity and a varied life, but only if they hold similar openness values. Moreover, there may be other reasons for the absence of dissimilarity effects on the self-transcendence versus self-enhancement dimension. That is, in addition to the influence of similarity threat, it may be that the effects of own and perceived values on this dimension are so robust that they supersede any potential value dissimilarity effects on prejudice. In other words, value dissimilarity may not convey additional negative 
information among individuals who are predisposed to dislike immigrants and who see immigrants' values negatively.

Finally, we also explored the possibility that dissimilarities between participants' perceptions of their ingroup values and the immigrant groups' values would predict prejudice, based on previous research in which intergroup dissimilarities have been theorized and found to predict prejudice (e.g., Schwartz et al., 1990; Stephan et al., 1999; Struch \& Schwartz, 1989). This past research on intergroup value dissimilarity has revealed similar issues as research on self-outgroup value dissimilarity, and we therefore used polynomial regression analyses and a focus on separate value dimensions to examine the link between intergroup value dissimilarity and prejudice in more detail. This exploratory test did not find support for this link, irrespective of which value types were considered, in line with previous suggestions that individuals react more strongly to individual-level threats than to group-level threats (Gaertner et al., 2002; Leonardelli et al., 2010). Nevertheless, it is important to emphasize that this was only an initial exploratory test and hence more research is needed to examine this link in more detail using polynomial regression analyses. For instance, future research could replicate this finding and examine whether perceptions of intergroup value dissimilarities do predict prejudice under certain circumstances, for instance when individuals identify more strongly with their ingroup as may be expected based on Jetten et al.'s (2004) meta-analysis.

It is worth noting two methodological changes between Study 1 on the one hand, and Studies 2 and 3 on the other. First, in Study 1, participants indicated their own values in a pre-test, 2-3 weeks prior to the main session, whereas own values were assessed at the end of the study, and hence after perceived values. We made this change because we reasoned that participants' own values should not be affected by the previous measures, given that values are generally relatively stable (Maio, 2016). In line with this notion, the correlations between own and perceived values, and between own values and the remaining measures were 
generally similar across all three studies. Second, in Study 1, participants received information about the percentage of the immigrant group living in the UK, which may have raised feelings of threat in participants (Outten, Lee, Costa-Lopes, Schmitt, \& Vala, 2018; Outten, Schmitt, Miller, \& Garcia, 2012). In Studies 2 and 3, participants did not receive such information. However, while this difference in information may have raised absolute levels of threat, Study 1 showed very similar relationships between values and prejudice as Studies 2 and 3. Nevertheless, it would be fruitful to further examine the circumstances that can change relationships between values, value dissimilarity, and prejudice. For instance, future research could test whether these relationships change when individuals are first encouraged to take the perspective of immigrants before they complete measures of perceived immigrant values and of favorability toward immigrants.

\section{Conclusion}

The present research used polynomial regression analyses to study the role of human values as a fundamental predictor of prejudice in an immigration context. The findings showed that values are linked with prejudice-related outcomes in a multi-faceted way. Perceptions of immigrants are more positive when individuals value self-transcendence principles (e.g., equality, helpfulness) more and self-enhancement principles less (e.g., power, achievement), and when they perceive immigrants to value self-transcendence principles more and self-enhancement principles less. The present research also provides the first evidence that abstract values relate to prejudice through the more concrete motivation to be nonprejudiced. Moreover, importantly, the present research showed for the first time that value dissimilarity effects differ depending on which value dimension is considered. Selfimmigrant value dissimilarity effects only occurred when immigrant groups were perceived to value openness but were absent for all other value types. Together, these findings help to clarify the longstanding argument that social values are central to prejudice by showing that 
their role is important but crucially dependent on which values (e.g., self-transcendence, openness) and types of effects (e.g., perceived values, dissimilarity) are being considered. 


\section{References}

Abbott, G. N., White, F. A., \& Charles, M. A. (2005). Linking values and organizational commitment: A correlational and experimental investigation in two organizations. Journal of Occupational and Organizational Psychology, 78(4), 531-551.

Akrami, N., Ekehammar, B., \& Araya, T. (2000). Classical and modern racial prejudice: A study of attitudes toward immigrants in Sweden. European Journal of Social Psychology, 30(4), 521-532.

Allport, G. W. (1954). The nature of prejudice. Reading, MA: Addison-Wesley.

Altemeyer, B. (1988). Enemies of freedom: Understanding right-wing authoritarianism. Jossey-Bass.

Barranti, M., Carlson, E. N., \& Côté, S. (2017). How to test questions about similarity in personality and social psychology research: Description and empirical demonstration of response surface analysis. Social Psychological and Personality Science, 8(4), 465475.

Bates, D., Maechler, M., Bolker, B., \& Walker, S. (2015). Fitting Linear Mixed Effects Models Using lme4. Journal of Statistical Software, 67(1), 1-48.

BBC. (2016, February). Attitudes harden towards refugees from Syria and Libya. Retrieved from http://www.bbc.co.uk/news/uk-england-35470723

Bernard, M. M., Maio, G. R., \& Olson, J. M. (2003). The vulnerability of values to attack: Inoculation of values and value-relevant attitudes. Personality and Social Psychology Bulletin, 29(1), 63-75.

Bilsky, W., Janik, M., \& Schwartz, S. H. (2011). The structural organization of human values - evidence from three rounds of the European Social Survey (ESS). Journal of CrossCultural Psychology, 42(5), 759-776.

Brewer, M. B. (1991). The social self: On being the same and different at the same time. Personality and Social Psychology Bulletin, 17(5), 475-482. 
Byrne, D. (1961). Interpersonal attraction and attitude similarity. The Journal of Abnormal and Social Psychology, 62(3), 713-715.

Byrne, D., \& Wong, T. J. (1962). Racial prejudice, interpersonal attraction, and assumed dissimilarity of attitudes. The Journal of Abnormal and Social Psychology, 65(4), 246253.

Davidov, E., Meuleman, B., Billiet, J., \& Schmidt, P. (2008). Values and support for immigration: A cross-country comparison. European Sociological Review, 24(5), 583599.

Deci, E. L., \& Ryan, R. M. (2000). The" what" and" why" of goal pursuits: Human needs and the self-determination of behavior. Psychological Inquiry, 11(4), 227-268.

Dovidio, J. F., \& Esses, V. M. (2001). Immigrants and immigration: Advancing the psychological perspective. Journal of Social Issues, 57(3), 378-387.

Dunbar, E., Saiz, J. L., Stela, K., \& Saez, R. (2000). Personality and social group value determinants of out-group bias: A cross-national comparison of Gough's Pr/To Scale. Journal of Cross-Cultural Psychology, 31(2), 267-275.

Dunwoody, P. T., \& McFarland, S. G. (2017). Support for Anti-Muslim Policies: The Role of Political Traits and Threat Perception. Political Psychology. https://doi.org/doi:10.1111/pops.12405

Edwards, J. R. (1993). Problems with the use of profile similarity indices in the study of congruence in organizational research. Personnel Psychology, 46(3), 641-665.

Edwards, J. R. (1994). The study of congruence in organizational behavior research: Critique and a proposed alternative. Organizational Behavior and Human Decision Processes, 58(1), 51-100.

Edwards, J. R. (2002). Alternatives to difference scores: Polynomial regression and response surface methodology. Advances in Measurement and Data Analysis, 350-400. 
Egri, C. P., \& Ralston, D. A. (2004). Generation cohorts and personal values: A comparison of China and the United States. Organization Science, 15(2), 210-220.

Esses, V. M., Dovidio, J. F., Jackson, L. M., \& Armstrong, T. L. (2001). The immigration dilemma: The role of perceived group competition, ethnic prejudice, and national identity. Journal of Social Issues, 57(3), 389-412.

Esses, V. M., Jackson, L. M., \& Armstrong, T. L. (1998). Intergroup competition and attitudes toward immigrants and immigration: An instrumental model of group conflict. Journal of Social Issues, 54(4), 699-724.

Esses, V. M., Medianu, S., \& Lawson, A. S. (2013). Uncertainty, threat, and the role of the media in promoting the dehumanization of immigrants and refugees. Journal of Social Issues, 69(3), 518-536.

Esses, V. M., Veenvliet, S., Hodson, G., \& Mihic, L. (2008). Justice, morality, and the dehumanization of refugees. Social Justice Research, 21(1), 4-25.

eurostat. (2017, March). Migration and migrant population statistics. Retrieved from http://ec.europa.eu/eurostat/statisticsexplained/index.php/Migration_and_migrant_population_statistics

Faul, F., Erdfelder, E., Lang, A.-G., \& Buchner, A. (2007). G* Power 3: A flexible statistical power analysis program for the social, behavioral, and biomedical sciences. Behavior Research Methods, 39(2), 175-191.

Feather, N. T., Norman, M. A., \& Worsley, A. (1998). Values and valences: Variables relating to the attractiveness and choice of food in different contexts. Journal of Applied Social Psychology, 28(7), 639-656.

Fox, J., \& Weisberg, Sanford (2011). An R Companion to Applied Regression, Second Edition. Thousand Oaks CA: Sage. 
Finegan, J. E. (2000). The impact of person and organizational values on organizational commitment. Journal of Occupational and Organizational Psychology, 73(2), 149169.

Gaertner, L., Sedikides, C., Vevea, J. L., \& Iuzzini, J. (2002). The 'I', the 'we', and the 'when': A meta-analysis of motivational primacy in self-definition. Journal of Personality and Social Psychology, 83(3), 574-591.

Goff, P. A., Jackson, M. C., Di Leone, B. A. L., Culotta, C. M., \& DiTomasso, N. A. (2014). The essence of innocence: Consequences of dehumanizing Black children. Journal of Personality and Social Psychology, 106(4), 526-545.

Gonsalkorale, K., Sherman, J. W., \& Klauer, K. C. (2009). Aging and prejudice: Diminished regulation of automatic race bias among older adults. Journal of Experimental Social Psychology, 45(2), 410-414.

Griffin, D., Murray, S., \& Gonzalez, R. (1999). Difference score correlations in relationship research: A conceptual primer. Personal Relationships, 6(4), 505-518.

Haddock, G., Zanna, M. P., \& Esses, V. M. (1993). Assessing the structure of prejudicial attitudes: The case of attitudes toward homosexuals. Journal of Personality and Social Psychology, 65(6), 1105-1118.

Heaven, P. C., Organ, L.-A., Supavadeeprasit, S., \& Leeson, P. (2006). War and prejudice: A study of social values, right-wing authoritarianism, and social dominance orientation. Personality and Individual Differences, 40(3), 599-608.

Hitlan, R. T., Carrillo, K., Zárate, M. A., \& Aikman, S. N. (2007). Attitudes toward immigrant groups and the September 11 terrorist attacks. Peace and Conflict: Journal of Peace Psychology, 13(2), 135-152.

Hornsey, M. J. (2008). Social identity theory and self-categorization theory: A historical review. Social and Personality Psychology Compass, 2(1), 204-222.

Humberg, S., Nestler, S., \& Back, M. D. (2018). Response Surface Analysis in personality 
and social psychology: checklist and clarifications for the case of congruence hypotheses. Social Psychological and Personality Science. Online first publication.

Insko, C. A., Nacoste, R. W., \& Moe, J. L. (1983). Belief congruence and racial discrimination: Review of the evidence and critical evaluation. European Journal of Social Psychology, 13(2), 153-174.

Jetten, J., Spears, R., \& Postmes, T. (2004). Intergroup distinctiveness and differentiation: a meta-analytic integration. Journal of personality and social psychology, 86(6), 862879.

Kinder, D. R., \& Sears, D. O. (1981). Prejudice and politics: Symbolic racism versus racial threats to the good life. Journal of Personality and Social Psychology, 40(3), 414-431.

Kingsley, P. (2015, August 10). 10 truths about Europe's migrant crisis. Retrieved from https://www.theguardian.com/uk-news/2015/aug/10/10-truths-about-europes-refugeecrisis

Lazarev, E., \& Sharma, K. (2015). Brother or Burden: An Experiment on Reducing Prejudice Toward Syrian Refugees in Turkey. Political Science Research and Methods, 1-19.

Legault, L., Green-Demers, I., Grant, P., \& Chung, J. (2007). On the Self-Regulation of Implicit and Explicit Prejudice A Self-Determination Theory Perspective. Personality and Social Psychology Bulletin, 33(5), 732-749.

Legault, L., Gutsell, J. N., \& Inzlicht, M. (2011). Ironic effects of antiprejudice messages how motivational interventions can reduce (but also increase) prejudice. Psychological Science, 22(12), 1472-1477.

Leonardelli, G. J., Pickett, C. L., \& Brewer, M. B. (2010). Optimal distinctiveness theory: A framework for social identity, social cognition, and intergroup relations. In Advances in experimental social psychology (Vol. 43, pp. 63-113). Academic Press. 
Leong, C.-H., \& Ward, C. (2006). Cultural values and attitudes toward immigrants and multiculturalism: The case of the Eurobarometer survey on racism and xenophobia. International Journal of Intercultural Relations, 30(6), 799-810.

Lindeman, M., \& Verkasalo, M. (2005). Measuring values with the short Schwartz's value survey. Journal of Personality Assessment, 85(2), 170-178.

Lorenzo-Seva, U., \& ten Berge, J. M. F. (2006). Tucker's congruence coefficient as a meaningful index of factor similarity. Methodology, 2(2), 57-64.

Maio, G. R. (2016). The psychology of human values. Psychology Press.

Maio, G. R., Bell, D. W., \& Esses, V. M. (1996). Ambivalence and persuasion: The processing of messages about immigrant groups. Journal of Experimental Social Psychology, 32(6), 513-536.

Maio, G. R., Esses, V. M., \& Bell, D. W. (1994). The formation of attitudes toward new immigrant groups. Journal of Applied Social Psychology, 24(19), 1762-1776.

McConahay, J. B., Hardee, B. B., \& Batts, V. (1981). Has racism declined in America? It depends on who is asking and what is asked. Journal of Conflict Resolution, 25(4), $563-579$.

Montoya, R. M., Horton, R. S., \& Kirchner, J. (2008). Is actual similarity necessary for attraction? A meta-analysis of actual and perceived similarity. Journal of Social and Personal Relationships, 25(6), 889-922.

Murray, K. E., \& Marx, D. M. (2013). Attitudes toward unauthorized immigrants, authorized immigrants, and refugees. Cultural Diversity and Ethnic Minority Psychology, 19(3), $332-341$.

Nosek, B. A., Banaji, M., \& Greenwald, A. G. (2002). Harvesting implicit group attitudes and beliefs from a demonstration web site. Group Dynamics: Theory, Research, and Practice, 6(1), 101-115. 
O’Driscoll, M., \& Feather, N. (1983). Perception of value congruence and interethnic behavioral intentions. International Journal of Intercultural Relations, 7(3), 239-252.

Office for National Statistics. (2012, December 11). 2011 Census: KS209EW Religion, local authorities in England and Wales. Retrieved from http://www.ons.gov.uk/ons/rel/census/2011-census/key-statistics-for-local-authoritiesin-england-and-wales/rft-table-ks209ew.xls

Office for National Statistics. (2017, May). Migration Statistics Quarterly Report: May 2017. Retrieved from https://www.ons.gov.uk/peoplepopulationandcommunity/populationandmigration/inte $\underline{\text { rnationalmigration/bulletins/migrationstatisticsquarterlyreport/may2017 }}$

Outten, H. R., Lee, T., Costa-Lopes, R., Schmitt, M. T., \& Vala, J. (2018). Majority Group Members' Negative Reactions to Future Demographic Shifts Depend on the Perceived Legitimacy of Their Status: Findings from the United States and Portugal. Frontiers in psychology, 9, 79 .

Outten, H. R., Schmitt, M. T., Miller, D. A., \& Garcia, A. L. (2012). Feeling threatened about the future: Whites' emotional reactions to anticipated ethnic demographic changes. Personality and Social Psychology Bulletin, 38(1), 14-25.

Pereira, C., Vala, J., \& Leyens, J. P. (2009). From infra-humanization to discrimination: The mediation of symbolic threat needs egalitarian norms. Journal of Experimental Social Psychology, 45(2), 336-344.

Pettigrew, T. F., \& Meertens, R. W. (1995). Subtle and blatant prejudice in Western Europe. European Journal of Social Psychology, 25(1), 57-75.

Plant, E. A., \& Devine, P. G. (1998). Internal and external motivation to respond without prejudice. Journal of personality and social psychology, 75(3), 811-832. 
Quillian, L. (1995). Prejudice as a response to perceived group threat: Population composition and anti-immigrant and racial prejudice in Europe. American Sociological Review, $586-611$.

R Core Team (2018). R: A language and environment for statistical computing. https://www.R-project.org/

Riek, B. M., Mania, E. W., \& Gaertner, S. L. (2006). Intergroup threat and outgroup attitudes: A meta-analytic review. Personality and Social Psychology Review, 10(4), 336-353.

Roccas, S., \& Amit, A. (2011). Group heterogeneity and tolerance: The moderating role of conservation values. Journal of Experimental Social Psychology, 47(5), 898-907.

Roccas, S., Schwartz, S. H., \& Amit, A. (2010). Personal value priorities and national identification. Political Psychology, 31(3), 393-419.

Rohan, M. J. (2000). A rose by any name? The values construct. Personality and Social Psychology Review, 4(3), 255-277.

Rohmann, A., Florack, A., \& Piontkowski, U. (2006). The role of discordant acculturation attitudes in perceived threat: An analysis of host and immigrant attitudes in Germany. International Journal of Intercultural Relations, 30(6), 683-702.

Rokeach, M. (1968). Beliefs, attitudes and values: A theory of organization and change.

Rokeach, M. (1973). The nature of human values (Vol. 438). Free press New York.

Rokeach, M., \& Mezei, L. (1966). Race and shared belief as factors in social choice. Science, 151(3707), 167-172.

Rokeach, M., Smith, P. W., \& Evans, R. I. (1960). Two kinds of prejudice or one. The Open and Closed Mind, 132-168.

Ros, M., Schwartz, S. H., \& Surkiss, S. (1999). Basic individual values, work values, and the meaning of work. Applied psychology, 48(1), 49-71.

Rosseel, Y. (2012). Lavaan: An R package for structural equation modeling. Journal of Statistical Software, 48(2), 1-36. 
Sagiv, L., \& Schwartz, S. H. (1995). Value priorities and readiness for out-group social contact. Journal of Personality and Social Psychology, 69(3), 437-448.

Saroglou, V., Lamkaddem, B., Van Pachterbeke, M., \& Buxant, C. (2009). Host society’s dislike of the Islamic veil: The role of subtle prejudice, values, and religion. International Journal of Intercultural Relations, 33(5), 419-428.

Schönbrodt, F. D. \& Humberg, S. (2018). RSA: An R package for response surface analysis (version 0.9.12). Retrieved from https://cran.r-project.org/package=RSA

Schönbrodt, F. D., \& Perugini, M. (2013). At what sample size do correlations stabilize? Journal of Research in Personality, 47(5), 609-612.

Schwartz, S. H. (1992). Universals in the content and structure of values: Theoretical advances and empirical tests in 20 countries. Advances in Experimental Social Psychology, 25(1), 1-65.

Schwartz, S. H. (1994). Are there universal aspects in the structure and contents of human values? Journal of social issues, 50(4), 19-45.

Schwartz, S. H. (2007). Value orientations: Measurement, antecedents and consequences across nations. Measuring Attitudes Cross-Nationally: Lessons from the European Social Survey, 161-193.

Schwartz, S. H., Caprara, G. V., \& Vecchione, M. (2010). Basic personal values, core political values, and voting: A longitudinal analysis. Political Psychology, 31(3), 421452.

Schwartz, S. H., Struch, N., \& Bilsky, W. (1990). Values and intergroup social motives: A study of Israeli and German students. Social Psychology Quarterly, 185-198.

Sherif, M., Harvey, O. J., White, B. J., Hood, W. R., Sherif, C. W., \& others. (1961). Intergroup conflict and cooperation: The Robbers Cave experiment (Vol. 10). Norman, OK: University Book Exchange. 
Stein, D. D., Hardyck, J. A., \& Smith, M. B. (1965). Race and belief: An open and shut case. Journal of Personality and Social Psychology, 1(4), 281-289.

Stephan, W. G., \& Renfro, C. L. (2002). The role of threats in intergroup relations. In D. Mackie \& E. R. Smith (Eds.), From prejudice to intergroup emotions (pp. 191-208). New York: Psychology Press.

Stephan, W. G., Renfro, C. L., Esses, V. M., Stephan, C. W., \& Martin, T. (2005). The effects of feeling threatened on attitudes toward immigrants. International Journal of Intercultural Relations, 29(1), 1-19.

Stephan, W. G., \& Stephan, C. W. (2017). Intergroup threat theory. The International Encyclopedia of Intercultural Communication, 1-12.

Stephan, W. G., Stephan, C. W., \& Oskamp, S. (2000). An integrated threat theory of prejudice. Reducing Prejudice and Discrimination, 23-45.

Stephan, W. G., Ybarra, O., \& Bachman, G. (1999). Prejudice Toward Immigrants. Journal of Applied Social Psychology, 29(11), 2221-2237.

Strabac, Z., \& Listhaug, O. (2008). Anti-Muslim prejudice in Europe: A multilevel analysis of survey data from 30 countries. Social Science Research, 37(1), 268-286.

Struch, N., \& Schwartz, S. H. (1989). Intergroup aggression: Its predictors and distinctness from in-group bias. Journal of Personality and Social Psychology, 56(3), 364-373.

Tajfel, H., \& Turner, J. C. (1979). An integrative theory of intergroup conflict. In W. G. Austin \& S. Worchel (Eds.), The Social Psychology of Intergroup Relations (pp. 3347). Monterey, CA: Brooks/Cole.

Tausch, N., Hewstone, M., Kenworthy, J., Cairns, E., \& Christ, O. (2007). Cross-community contact, perceived status differences, and intergroup attitudes in Northern Ireland: The mediating roles of individual-level versus group-level threats and the moderating role of social identification. Political Psychology, 28(1), 53-68. 
Turner, J. C., Hogg, M. A., Oakes, P. J., Reicher, S. D., \& Wetherell, M. S. (1987).

Rediscovering the Social Group: A self-categorization Theory. New York: Blackwell.

UNHCR. (2016, June). Global trends: Forced displacement in 2015. Retrieved from

https://s3.amazonaws.com/unhcrsharedmedia/2016/2016-06-20-global-trends/201606-14-Global-Trends-2015.pdf

Vala, J., Pereira, C., \& Ramos, A. (2006). Racial prejudice, threat perception and opposition to immigration: A comparative analysis. Portuguese Journal of Social Science, 5(2), 119-140.

Vecchione, M., Caprara, G., Schoen, H., Castro, J. L. G., \& Schwartz, S. H. (2012). The role of personal values and basic traits in perceptions of the consequences of immigration: A three-nation study. British Journal of Psychology, 103(3), 359-377.

Velasco González, K., Verkuyten, M., Weesie, J., \& Poppe, E. (2008). Prejudice towards Muslims in the Netherlands: Testing integrated threat theory. British Journal of Social Psychology, 47(4), 667-685.

Verkuyten, M. (2004). Emotional reactions to and support for immigrant policies: Attributed responsibilities to categories of asylum seekers. Social Justice Research, 17(3), 293314.

Weinstein, N., Przybylski, A. K., \& Ryan, R. M. (2012). The index of autonomous functioning: Development of a scale of human autonomy. Journal of Research in Personality, 46(4), 397-413.

Wolf, L. J., Maio, G. R., Karremans, J. C., \& Leygue, C. (2017). On implicit racial prejudice against infants. Group Processes \& Intergroup Relations, 20(6), 789-800.

YouGov. (2015, November). Brits less accepting of Syrian refugees in wake of Paris attacks. Retrieved from https://d25d2506sfb94s.cloudfront.net/cumulus_uploads/document/58hsi5v1r3/Times Results_151117_ParisBombing_Website.pdf 
Table 1.

Results of Polynomial Regression Analyses for Both Value Dimensions on Evaluation in all Three Studies.

\section{Study 1}

Study 2

Study 3

\begin{tabular}{lcccccccccc}
\hline & \multicolumn{2}{c}{ Muslim immigrants } & \multicolumn{2}{c}{ Economic migrants } & \multicolumn{2}{c}{ Refugees } & \multicolumn{2}{c}{ Economic migrants } & \multicolumn{2}{c}{ Refugees } \\
\hline ST & $b(S E)$ & $\beta$ & $b(S E)$ & $\beta$ & $b(S E)$ & $\beta$ & $b(S E)$ & $\beta$ & $b(S E)$ & $\beta$ \\
\hline Own & $0.24(.08)$ & $.27^{* *}$ & $0.24(.11)$ & $.21 \dagger$ & $0.32(.10)$ & $.29^{* * *}$ & $0.41(.12)$ & $.37^{* *}$ & $0.26(.13)$ & $.23 \dagger$ \\
Per & $0.38(.07)$ & $.50^{* * *}$ & $0.21(.09)$ & $.28^{*}$ & $0.39(.10)$ & $.38^{* * *}$ & $0.13(.10)$ & .16 & $0.26(.14)$ & .23 \\
Own*Per & $0.02(.10)$ & .02 & $0.01(.09)$ & .01 & $0.08(.13)$ & .07 & $-0.15(.13)$ & -.22 & $0.07(.11)$ & .09 \\
Own $^{2}$ & $0.06(.06)$ & .13 & $-0.03(.09)$ & -.05 & $-0.11(.09)$ & -.19 & $-0.07(.09)$ & -.13 & $-0.12(.09)$ & -.21 \\
Per $^{2}$ & $-0.07(.03)$ & $-.21^{*}$ & $-0.10(.06)$ & -.22 & $0.02(.06)$ & .04 & $0.00(.06)$ & -.01 & $-0.17(.08)$ & $-.27 \dagger$ \\
\hline Con & $b(S E)$ & $\beta$ & $b(S E)$ & $\beta$ & $b(S E)$ & $\beta$ & $b(S E)$ & $\beta$ & $b(S E)$ & $\beta$ \\
\hline Own & $-0.03(.08)$ & -.04 & $-0.13(.07)$ & -.16 & $-0.06(.07)$ & -.08 & $-0.10(.07)$ & -.15 & $-0.23(.09)$ & $-.27^{*}$ \\
Per & $0.02(.07)$ & .03 & $-0.02(.10)$ & -.03 & $-0.21(.08)$ & $-.23^{*}$ & $-0.04(.11)$ & .05 & $0.10(.12)$ & .10 \\
Own*Per & $0.18(.09)$ & $.19 \dagger$ & $-0.05(.08)$ & -.06 & $0.14(.08)$ & .16 & $0.08(.09)$ & .18 & $0.19(.08)$ & $.36^{*}$ \\
Own $^{2}$ & $0.02(.04)$ & .05 & $-0.03(.05)$ & -.07 & $0.02(.05)$ & .05 & $0.00(.05)$ & .01 & $-0.08(.06)$ & -.25 \\
Per $^{2}$ & $0.01(.05)$ & .04 & $0.09(.05)$ & .21 & $0.02(.05)$ & .05 & $-0.10(.08)$ & -.15 & $-0.01(.09)$ & -.01 \\
\hline
\end{tabular}

Note. Polynomial regression analyses regressed evaluations of Muslim immigrants, economic migrants, or refugees onto participants' own and perceived immigrant values in the first step, their interaction term in the second step, and their quadratic terms in the third step. Analyses simultaneously included self-transcendence versus self-enhancement values dimension ('ST') and conservation versus openness values dimension ('Con'). Own=own values; per=perceived values. $\dagger$ conventionally significant at $.05, *$ significant at $.025, * *$ significant at $.005, * * *$ significant at .0005 . 
Table 2.

Results of Polynomial Regression Analyses for Both Value Dimensions on Symbolic Threat in all Three Studies.

\section{Study 1}

Study 2

Study 3

\begin{tabular}{lcccccccccc}
\hline & \multicolumn{1}{c}{ Muslim immigrants } & \multicolumn{2}{c}{ Economic migrants } & \multicolumn{2}{c}{ Refugees } & \multicolumn{2}{c}{ Economic migrants } & \multicolumn{2}{c}{ Refugees } \\
\hline ST & $b(S E)$ & $\beta$ & $b(S E)$ & $\beta$ & $b(S E)$ & $\beta$ & $b(S E)$ & $\beta$ & $b(S E)$ & $\beta$ \\
\hline Own & $-0.47(.11)$ & $-.34^{* * *}$ & $-0.44(.15)$ & $-.27^{* *}$ & $-0.43(.16)$ & $-.25^{*}$ & $-0.54(.17)$ & $-.34^{* *}$ & $-0.45(.18)$ & $-.29^{*}$ \\
Per & $-0.70(.09)$ & $-.60^{* * *}$ & $-0.37(.13)$ & $-.33^{* *}$ & $-0.43(.15)$ & $-.28^{*}$ & $-0.25(.14)$ & -.21 & $-0.23(.19)$ & -.14 \\
Own*Per & $-0.09(.13)$ & -.06 & $0.05(.13)$ & .04 & $-0.05(.20)$ & -.03 & $0.07(.18)$ & .07 & $-0.07(.15)$ & -.06 \\
Own $^{2}$ & $0.07(.08)$ & .09 & $0.07(.12)$ & .08 & $0.06(.15)$ & .07 & $0.21(.12)$ & .25 & $0.02(.12)$ & .03 \\
Per $^{2}$ & $0.09(.04)$ & $.19^{*}$ & $0.06(.08)$ & .09 & $-0.01(.10)$ & -.01 & $-0.01(.08)$ & -.02 & $0.33(.11)$ & $.38^{* *}$ \\
\hline Con & $b(S E)$ & $\beta$ & $b(S E)$ & $\beta$ & $b(S E)$ & $\beta$ & $b(S E)$ & $\beta$ & $b(S E)$ & $\beta$ \\
\hline Own & $0.01(.10)$ & .01 & $0.26(.10)$ & $.22^{*}$ & $0.13(.11)$ & .11 & $0.16(.11)$ & .16 & $0.38(.12)$ & $.32^{* *}$ \\
Per & $0.01(.10)$ & .01 & $0.06(.14)$ & .05 & $0.21(.13)$ & .16 & $0.00(.15)$ & .00 & $-0.17(.16)$ & -.11 \\
Own*Per & $-0.33(.12)$ & $-.22 *$ & $0.02(.11)$ & .01 & $-0.25(.13)$ & -.20 & $-0.06(.13)$ & -.09 & $-0.26(.11)$ & $-.36^{*}$ \\
Own $^{2}$ & $-0.03(.06)$ & -.06 & $0.08(.07)$ & .17 & $0.03(.07)$ & .06 & $0.05(.07)$ & .15 & $0.13(.08)$ & .29 \\
Per $^{2}$ & $-0.04(.06)$ & -.12 & $-0.04(.07)$ & -.07 & $0.04(.08)$ & .05 & $0.06(.11)$ & .06 & $0.09(.12)$ & .09 \\
\hline
\end{tabular}

Note. Polynomial regression analyses regressed perceptions of symbolic threat from Muslim immigrants, economic migrants, or refugees onto participants' own and perceived immigrant values in the first step, their interaction term in the second step, and their quadratic terms in the third step. Analyses simultaneously included self-transcendence versus self-enhancement values dimension ('ST') and conservation versus openness values dimension ('Con'). Own=own values; per=perceived values. $\dagger$ value below $.05, *$ significant at $.025, * *$ significant at $.005, * * *$ significant at .0005 . 
Table 3.

Means, Standard Deviations, and Correlations of all Variables in Study 1.

\begin{tabular}{lccccccc} 
Variables & $M(S D)$ & 1 & 2 & 3 & 4 & 5 & 6 \\
\hline 1. Own ST & $0.85(1.22)^{\mathrm{a}}$ & & & & & & \\
2. Per ST & $0.43(1.33)^{\mathrm{a}}$ & .06 & & & & & \\
3. Own Con & $-0.72(1.27)^{\mathrm{a}}$ & $-.23 *$ & -.15 & & & & \\
4. Per Con & $1.78(1.26)^{\mathrm{a}}$ & .14 & .04 & -.19 & & & \\
5. MNPS & $1.78(1.35)$ & $.46 * * *$ & $.32 * *$ & $-.38 * * *$ & .10 & & \\
6. Symb & $4.34(1.55)$ & $-.37 * * *$ & $-.62 * * *$ & .18 & -.07 & $-.47 * * *$ & \\
7. Eva & $5.08(1.01)$ & $.31^{* *}$ & $.52^{* * *}$ & -.18 & .09 & $.61 * * *$ & $-.76 * * *$ \\
\hline
\end{tabular}

Note. Possible scores range approximately from -9 to +9 on the self-transcendence versus self-enhancement values dimension ('ST') and on the conservation openness dimension ('Con'), with more positive scores indicating higher self-transcendence and conservation values than self-enhancement and openness values. Possible scores on the MNPS range from -36 to +36 , with more positive scores indicating a more internalized motivation to be nonprejudiced. Possible scores on 'symb' range from 1 to 10 with higher scores indicating higher perceived symbolic threat. Possible scores on 'eva' range from 1 to 7 , with higher scores indicating more positive evaluations of Muslim immigrants. * correlation significant at .05 , $* *$ significant at $.01, * * *$ significant at $.001 .{ }^{\text {a }}$ value score significantly different from 0 . 
Table 6 .

Means, Standard Deviations, and Correlations of all Variables in Study 2.

\begin{tabular}{|c|c|c|c|c|c|c|c|c|c|c|c|c|c|}
\hline Variables & $M(S D)$ & 1 & 2 & 3 & 4 & 5 & 6 & 7 & 8 & 9 & 10 & 11 & 12 \\
\hline 1. Own ST & $0.51(0.84)^{\mathrm{a}}$ & & & & & & & & & & & & \\
\hline 2. Own Con & $-0.55(1.19)^{\mathrm{a}}$ & -.02 & & & & & & & & & & & \\
\hline 3. Eco ST & $-0.26(1.23)^{\mathrm{a}}$ & .17 & .12 & & & & & & & & & & \\
\hline 4. Eco Con & $0.12(1.11)$ & -.06 & .08 & $.59 * * *$ & & & & & & & & & \\
\hline 5. Eco eva & $4.62(0.95)$ & $.26 * *$ & -.14 & $.28 * *$ & .11 & & & & & & & & \\
\hline 6. Eco symb & $4.54(1.37)$ & $-.33 * * *$ & .19 & $-.32 * * *$ & -.10 & $-.74 * * *$ & & & & & & & \\
\hline 7. Eco des & $4.70(1.10)$ & .18 & -.11 & $.33 * * *$ & .12 & $.49 * * *$ & $-.53 * * *$ & & & & & & \\
\hline 8. Ref ST & $1.04(0.92)^{\mathrm{a}}$ & .19 & -.07 & $.28 * *$ & .18 & $.27 * *$ & $-.24 *$ & .02 & & & & & \\
\hline 9. Ref Con & $0.50(1.06)^{\mathrm{a}}$ & .02 & -.01 & $.28 * *$ & $.53 * * *$ & -.01 & .00 & -.08 & $.34 * * *$ & & & & \\
\hline 10. Ref eva & $5.02(0.95)$ & $.36 * * *$ & -.11 & .12 & -.02 & $.65 * * *$ & $-.56 * * *$ & $.43 * * *$ & $.36^{* * *}$ & -.10 & & & \\
\hline 11. Ref symb & $4.40(1.43)$ & $-.31 * * *$ & .13 & -.17 & -.05 & $-.61 * * *$ & $.84 * * *$ & $-.46 * * *$ & $-.28 * *$ & .05 & $-.69 * * *$ & & \\
\hline 12. Ref des & $6.03(0.92)$ & $.36 * * *$ & -.16 & .12 & .07 & $.41 * * *$ & $-.49 * * *$ & $.50 * * *$ & $.24 *$ & -.14 & $.78 * * *$ & $-.62 * * *$ & \\
\hline 13. MNPS & $1.74(1.16)$ & $.30 * *$ & -.09 & .13 & .09 & $.51 * * *$ & $-.50 * * *$ & $.39 * * *$ & .12 & -.07 & $.49 * * *$ & $-.51 * * *$ & $.55^{* * *}$ \\
\hline
\end{tabular}

Note. Possible scores range approximately from -5 to +5 on the self-transcendence versus self-enhancement values dimension ('ST') and from -6 to +6 on the conservation openness dimension ('Con'), with more positive scores indicating higher self-transcendence and conservation values than self-enhancement and openness values. Possible scores on the MNPS range from -36 to +36 , with more positive scores indicating a more internalized motivation to be non-prejudiced. Possible scores on 'eva', 'symb', and 'des' range from 1 to 7 , with higher scores indicating more positive evaluations, lower perceived symbolic threat, and higher perceived deservingness of help toward economic migrants ('eco') and refugees. * correlation significant at .05, ** significant at .01, *** significant at .001. ${ }^{\text {a }}$ value score significantly different from 0 . 
Table 5 .

Means, Standard Deviations, and Correlations of all Variables in the Economic Migrants Condition in Study 3.

\begin{tabular}{|c|c|c|c|c|c|c|c|c|c|c|}
\hline Variables & $M(S D)$ & 1 & 2 & 3 & 4 & 5 & 6 & 7 & 8 & 9 \\
\hline 1. Own ST & $0.50(0.78)^{\mathrm{a}}$ & & & & & & & & & \\
\hline 2. Eco ST & $0.48(1.07)^{\mathrm{a}}$ & .18 & & & & & & & & \\
\hline 3. Own Con & $-1.21(1.26)^{\mathrm{a}}$ & -.02 & -.15 & & & & & & & \\
\hline 4. Eco Con & $0.19(0.98)$ & .06 & $.44 * * *$ & $-.26^{*}$ & & & & & & \\
\hline 5. MNPS & $2.02(1.41)$ & $.33 * *$ & $.23 *$ & $-.27 *$ & .19 & & & & & \\
\hline 6. Eco eva & $5.14(0.87)$ & $.40 * * *$ & $.22 *$ & -.17 & .08 & $.65 * * *$ & & & & \\
\hline 7. Eco symb & $4.18(1.26)$ & $-.38 * * *$ & $-.29 * *$ & .20 & -.15 & $-.65 * * *$ & $-.82 * * *$ & & & \\
\hline 8. Eco des & $5.04(0.82)$ & .17 & $.46^{* * *}$ & -.17 & $.32 * *$ & $.24 *$ & $.33 * *$ & $-.27 *$ & & \\
\hline 9. Eco zero & $3.25(1.27)$ & $-.29 * *$ & $-.27 *$ & .16 & -.15 & $-.49 * * *$ & $-.67 * * *$ & $.71 * * *$ & $-.41 * * *$ & \\
\hline
\end{tabular}

\begin{tabular}{llllllllll} 
9. Eco zero & $3.25(1.27)$ & $-.29 * *$ & $-.27 *$ & .16 & -.15 & $-.49 * * *$ & $-.67 * * *$ & $.71 * * *$ & $-.41^{* * *}$ \\
\hline Note. Possible scores range approximately from -5 to +5 on the self-transcendence versus self-enhancement values
\end{tabular} dimension ('ST') and from -6 to +6 on the conservation openness dimension ('Con'), with more positive scores indicating higher importance of self-transcendence and conservation values than self-enhancement and openness values. Possible scores on the MNPS range from -36 to +36 , with more positive scores indicating a more internalized motivation to be nonprejudiced. Possible scores on 'eva', 'symb', 'des' and 'zero' range from 1 to 7, with higher scores indicating more positive evaluations, higher perceived symbolic threat, higher perceived deservingness, and higher zero-sum beliefs toward economic migrants. Own $=$ own values; eco=perceived values of economic migrants. $*$ correlation significant at $.05, * *$ significant at $.01, * * *$ significant at .001 . a value score significantly different from 0 . 
Table 6 .

Means, Standard Deviations, and Correlations of all Variables in the Refugees Condition in Study 3.

\begin{tabular}{|c|c|c|c|c|c|c|c|c|c|c|}
\hline Variables & $M(S D)$ & 1 & 2 & 3 & 4 & 5 & 6 & 7 & 8 & 9 \\
\hline 1. Own ST & $0.53(0.97)^{\mathrm{a}}$ & & & & & & & & & \\
\hline 2. Ref ST & $1.31(0.94)^{\mathrm{a}}$ & $.36^{* * *}$ & & & & & & & & \\
\hline 3. Own Con & $-1.25(1.29)^{\mathrm{a}}$ & .13 & -.07 & & & & & & & \\
\hline 4. Ref Con & $0.27(1.03)^{\mathrm{a}}$ & -.07 & $.28 *$ & .05 & & & & & & \\
\hline 5. MNPS & $1.67(1.35)$ & $.27^{*}$ & $.26^{*}$ & $-.41 * * *$ & .11 & & & & & \\
\hline 6. Ref eva & $5.11(1.09)$ & $.28^{*}$ & $.36^{* * *}$ & $-.25^{*}$ & .13 & $.70 * * *$ & & & & \\
\hline 7. Ref symb & $4.32(1.54)$ & $-.29 * *$ & $-.30 * *$ & $.29 * *$ & -.11 & $-.69 * * *$ & $-.75 * * *$ & & & \\
\hline 8. Ref des & $5.59(1.00)$ & $.28^{*}$ & $.51 * * *$ & $-.36 * * *$ & .12 & $.63 * * *$ & $.78 * * *$ & $-.76 * * *$ & & \\
\hline 9. Ref zero & $3.18(1.52)$ & $-.29 * *$ & -.20 & $-.33 * *$ & -.05 & $-.61 * * *$ & $-.73 * * *$ & $.80 * * *$ & $-.73 * * *$ & \\
\hline
\end{tabular}

\begin{tabular}{llllllllll}
9. Ref zero & $3.18(1.52)$ & $-.29 * *$ & -.20 & $-.33 * *$ & -.05 & $-.61 * * *$ & $-.73 * * *$ & $.83^{* * *}$ & $-.73 * * *$ \\
\hline Note. Possible scores range approximately from -5 & to +5 on the self-transcendence versus self-enhancement values
\end{tabular} dimension ('ST') and from -6 to +6 on the conservation openness dimension ('Con'), with more positive scores indicating higher importance of self-transcendence and conservation values than self-enhancement and openness values. Possible scores on the MNPS range from -36 to +36 , with more positive scores indicating a more internalized motivation to be nonprejudiced. Possible scores on 'eva', 'symb', 'des' and 'zero' range from 1 to 7 , with higher scores indicating more positive evaluations, higher perceived symbolic threat, higher perceived deservingness, and higher zero-sum beliefs toward refugees. Own=own values; ref=perceived values of refugees. $*$ correlation significant at .05 , ** significant at $.01, * * *$ significant at $.001 .{ }^{\mathrm{a}}$ value score significantly different from 0 . 
${ }^{1}$ The additional item correlated .65 with the total of the remaining items of the scale, and excluding the item would reduce the reliability of the scale somewhat from .86 to .84 .

${ }^{2}$ In all three studies, this measure also contained ten additional items assessing perceived realistic threat from Muslim immigrants. Given that these were not central to our research question, they are not considered further.

${ }^{3}$ In all three studies, we asked participants to estimate how many immigrants the UK can accept each year. In addition, we administered the one-item Inclusion of the Other in the Self scale (Aron et al., 1992), which assesses the amount of perceived closeness to the target person. Given that these items were not relevant to our research question, they are not discussed further.

${ }^{4}$ While the original MNPS asked participants to indicate their "ultimate reasons for avoiding prejudice" in general, and hence not against a specific target group, we decided to directly mention the respective target group in all three studies. It is noteworthy that we do not assume that participants' motivation to control prejudice differs among these target groups; instead the intention was to make the scale more concrete and relevant to the general scope of the study, thus hopefully increasing its comprehensibility for participants.

${ }^{5}$ In Study 1, we also administered participants' dispositional autonomy with the Index of Autonomous Functioning scale (IAF; Weinstein, Przybylski, \& Ryan, 2012). This measure was not central to our research question and is hence not discussed further.

${ }^{6}$ We used the MNPS rather than Plant and Devine's (1998) internal and external motivation to respond without prejudice, because previous evidence indirectly supported a link between the MNPS and values (Legault et al., 2011).

${ }^{7}$ Response surface analyses (RSA) also provide statistical tests for four coefficients that examine different aspects of similarity effects. Given that these coefficients are 
straightforward combinations of the polynomial regression weights, we reasoned that this information was covered in more detail in our main analyses. All RSA coefficients of each study can be found in the supplement (for a good explanation of these RSA coefficients, see Barranti et al., 2017).

${ }^{8}$ Both Studies 2 and 3 explored differences in perceptions of refugees and economic migrants. Study 2 assessed to what extent the groups were perceived as deserving of help, and Study 3 additionally assessed perceived competition with each group by using Esses et al.'s (1998) zero-sum beliefs measure. Across both studies, refugees were perceived to be higher in selftranscendence values, and higher in deservingness of help, whereas evaluation, symbolic threat, conservation versus openness values, and zero-sum beliefs did not consistently differ between the groups. We have described these additional analyses in more detail in the online supplement.

${ }^{9}$ In Studies 2 and 3, we additionally assessed how familiar participants are with Syria, with refugees, with Jordan, and with economic migrants. We also asked whether they know any Syrians, refugees, Jordanians, or economic migrants personally. These measures were not central to our main research question and are hence not considered further.

${ }^{10}$ To check whether participants kept the framings of the immigrants in mind, we asked participants at the end of the study to indicate the immigrants' reasons for coming to the UK (i.e., refugee vs. economic). One participant did not correctly recall the reasons for immigration. However, the results remained the same when this participant was excluded, and we therefore retained this participant for all analyses in Study 2.

${ }^{11}$ Given that we eventually conducted all analyses across target groups, the achieved power to detect a medium effect size was .98

${ }^{12}$ After the MNPS, we administered the identification with all humanity scale (McFarland, Webb, \& Brown, 2012). This scale was not relevant for our research question and is not considered further. 
${ }^{13}$ As in Study 2, we checked whether participants kept the framings of the immigrants in mind. All participants passed this knowledge check. 